\title{
High School Track Choice and Liquidity Constraints: Evidence from Urban Mexico*
}

\author{
Ciro Avitabile ${ }^{\dagger} \quad$ Matteo Bobba ${ }^{\ddagger} \quad$ Marco Pariguana ${ }^{\S}$ \\ May 2017
}

\begin{abstract}
We study how a large household windfall affects sorting of relatively disadvantaged youth over high school tracks by exploiting the discontinuity in the assignment of a welfare program in Mexico. The in-cash transfer is found to significantly increase the probability of selecting vocational schools as the most preferred options vis-a-vis other more academically oriented education modalities. We find support for the hypothesis that the receipt of unearned income allows some students to choose a schooling career with higher out-of-pocket expenditures and higher expected returns. The observed change in stated preferences across tracks effectively alters school placement, and bears a positive effect on later education outcomes.
\end{abstract}

Keywords: school choice, tracking, financial constraints, vocational education, returns to education, regression discontinuity design.

JEL Codes: I21; I24; J24.

\footnotetext{
*We are grateful to the Mexican Ministry of Education (SEP) and the Oportunidades program (recently renamed PROSPERA Programa de Inclusión social) for kindly providing us with access to the data, and to Jose Guadalupe Fernandez Galarza for his invaluable help with the COMIPEMS database. For useful comments we also thank Caridad Araujo, Andrew Dustan, Ricardo Estrada, Veronica Frisancho, Alex Solis, as well as the audiences at various seminars and conferences.

${ }^{\dagger}$ University of Surrey and World Bank. E-mail: c.avitabile@surrey.ac.uk.

$\ddagger$ Toulouse School of Economics, University of Toulouse Capitole. E-mail: matteo.bobba@tse-fr.eu.

$\S$ Department of Economics, University of Western Ontario. E-mail: mparigua@uwo.ca.
} 


\section{Introduction}

Returns to education vary dramatically across academic fields and tracks [Altonji et al., 2012, 2016]. In most countries youth start facing important curricular choices at the upper secondary education level. While better preparing those students who plan to pursue tertiary education, academically oriented secondary school curriculums often provide no relevant job market skills for those who do not have the talent, the interest, or the financial resources to continue their studies. ${ }^{1}$ In many contexts, and especially in developing countries, the vast majority of secondary school students attend academically oriented programs. For instance, in the year 2013 the share of students enrolled in vocational education programs in Latin America and Caribbean (LAC) and Sub-Saharan Africa were about 15 percent and 11 percent, respectively, as opposed to 44 percent in OECD countries (World Bank EdStats). While arguments from both the supply side (e.g. higher running costs of instruction and facilities) and the demand side (e.g. quality concerns, lack of information about the potential returns, and social norms) may potentially explain these patterns, there is very little systematic evidence on the determinants of curricular choices in upper secondary education. ${ }^{2}$

This paper studies the role of liquidity constraints in shaping the demand for vocational education. Specifically, we evaluate the extent to which a large household cash subsidy can affect sorting over high school tracks of relatively disadvantaged youth living in a suburban district of Mexico City. The centralized school assignment mechanism currently in place gives us the unique opportunity to observe individual stated preferences over education modalities for the quasi-universe of public upper secondary education programs in the area. We combine these data with individual registries within a selected municipality on the roll-out of the social assistance program, Oportunidades, which provides cash transfers conditional on household members' behavior in health and children's attendance at school (but not on the type of school attended). The in-cash subsidy is sizable, amounting to roughly one-third of the median household income in our sample. The discontinuity in the program assignment based

\footnotetext{
${ }^{1}$ Evidence from both developed and developing countries seems to suggest that among secondary school graduates, the private net returns to vocational education exceed those of general education [Altonji, 1995; Di Gropello, 2006; Meer, 2007]. Relatedly, rigorous studies from selected developing countries (Attanasio et al. [2011, 2015] for Colombia and Card et al. [2011] for Dominican Republic) support the hypothesis that vocational education and training (VET) programs have the potential to provide young adults with the skills needed for the labor market.

${ }^{2}$ Few recent exceptions are Buser et al. [2014], that study the role of a personality trait (competitiveness) as a determinant of high school track choices in the Netherland; Giustinelli [2016], focusing on how subjective expected utilities of both parents and students shape high school track choices in Italy; Bobba and Frisancho [2016], that consider the role of students' self-perceptions about academic ability as a potential determinant of track choices in the same context as in this paper.
} 
on a pre-determined poverty score allows us to establish the causal effects of the transfer on high school track choices by comparing households just above and below the eligibility threshold.

Mexico represents an archetypical setting in which to study curricular choices in developing countries. When completing the lower secondary level, students can choose from amongst three different education modalities (general, technical, and vocational) that greatly differ in the extent to which they prepare students to enter the labor market. The vocational track is associated with better labor market outcomes for those individuals who do not complete tertiary education, but it also entails higher out-of-pocket expenditures - i.e. tuition and transportation costs - when compared with the other more academically-oriented tracks. In the year 2013, only 10 percent of high school students enrolled in the vocational track. On-time graduation rates vary across types of degree programs with general schools showing the highest (64 percent), followed by technical schools with rates very close to the national average (61 percent) and vocational schools showing the lowest (48 percent). The prevalence of high school enrollment in the general and technical tracks - the most academically oriented high school curriculums - is somehow in contrast with the very low gross enrollment rate in higher education (29 percent in 2013), especially among the poorest.

Our estimates show that eligibility for the Oportunidades cash transfers increases the probability of choosing a high school offering the vocational curriculum as the first option by $4-5$ percentage points. When we account for the imperfect compliance with the program, we find that the probability of choosing the vocational track as first option increases by 6-7 percentage points, which is equivalent to a nearly 60 percent increase with respect to the sample average. This effect is due to changes in stated preferences over schools among applicants at the bottom of the distribution of academic achievement in lower secondary: a result that squares well with both observed and expected labor market returns to high school tracks in Mexico. Consistently with the hypothesis that liquidity constraints prevent some students from choosing their preferred high school programs, the effects of cash transfers on track choices are concentrated among those with limited access to vocational programs (in terms of greater distance from their places of residence). In addition, as a result of the income shock and unconditionally on the chosen preferred track, students tend to select first options with higher tuition fees and that are located further away from their places of residence.

We also find that Oportunidades recipients are more likely to be assigned to their preferred schooling option. Placement in the school assignment system depends solely on students' 
stated preferences and their performance in the admission exam, both of which are observable in the data. Since we do not observe any significant change in the score of the admission exam around the program eligibility cutoff, we interpret the effect of the cash transfer on school assignment to be driven by the program-induced changes in preferences over schools. In addition, among those students who attended a vocational option, those who belong to Oportunidades beneficiary households are more likely to complete high school on time than those who do not belong to beneficiary households. All together the available evidence is consistent with the hypothesis that the change in school choices triggered by the receipt of the cash transfers can have a persistent impact on educational outcomes later on - a result that is consistent with previous findings in the literature [Angrist et al., 2006; Deming et al., 2014].

More broadly, this paper speaks to a large body of empirical work that explores the effects of household income and/or access to credit on human capital investments (see Lochner and Monge-Naranjo [2012] for a review). There is now well-established evidence that direct costs of education are an important determinant of schooling decisions in developing countries [Angrist et al., 2002; Duflo et al., 2015; Lucas and Mbiti, 2012; Schultz, 2004]. We contribute to this literature by showing that cash transfers can have important consequences not only for the extensive margins of schooling investments (i.e. enrollment and completion rates) but also for one intensive margin (i.e. curricular choices), which can bear long-term consequences on future academic trajectories and labor market outcomes [Dustmann et al., 2014].

Although we cannot directly link school choices and assignment outcomes to subsequent labor market trajectories, our results suggest that high school track decisions may provide an alternative mechanism through which the distribution of income can influence occupational choices. In fact, early theoretical work [Banerjee and Newman, 1993; Ghatak et al., 2001] and more recent empirical evidence had primarily focused on the lack of credit collateral and the limited access to insurance mechanisms when explaining why poorer people are less likely to be self-employed. ${ }^{3}$

\footnotetext{
${ }^{3}$ For instance, Banerjee et al. [2015]; Tarozzi et al. [2015] find that microcredit programs lead to a small but statistically significant effect on the probability of being self-employed. Blattman et al. [2014] finds in Uganda that individuals who receive unsupervised grants are more likely to become self-employed. Studying the implementation in rural areas of the same program studied in this paper (previously named Progresa), Bianchi and Bobba [2013] find that cash transfers increase entry into entrepreneurship through increased willingness to bear risk, rather than by relaxing current liquidity constraints.
} 


\section{Context and Data}

\subsection{The School Assignment Mechanism}

Students who want to attend a public high school in the urban area of Mexico City are required to participate in a centralized assignment mechanism, regulated and administered by the Metropolitan Commission of Higher Secondary Public Education Institutions (COMIPEMS, by its Spanish acronym). Since 1996, the commission brings together nine schooling subsystems that have agreed to select candidates through an exam-based admission process. ${ }^{4}$ Each year the system offers approximately 250,000 seats in 700 public schools located in Mexico's Federal District, as well as 22 urban municipalities in the neighboring State of Mexico. This roughly corresponds to 75 percent of the total high school enrollment in the area (10 percent of students are matriculated in other public schools outside of the COMIPEMS system and 15 percent in private schools).

In late January of each year, students in the ninth grade - the final year of middle school - receive information on the admission process. These materials include a list of all available educational options (which in most cases are schools but can also be specific tracks within a school), a measure of the extent to which options feature an excess demand for previous cohorts of applicants, detailed information about the schooling curriculum, as well as the general and specific skills provided. Applicants complete a registration form, a sociodemographic survey, and a list of up to 20 educational options, which they rank in order of preference. In June of the same year, applicants take a standardized exam consisting of 128 multiple choice questions, covering both subject-specific material from the public school curriculum as well as general mathematical and language skills material. The process of school assignment is carried out in July following a serial dictatorship algorithm that is a special case of the deferred acceptance algorithm characterized by Gale and Shapley [1962]. ${ }^{5}$

\footnotetext{
${ }^{4}$ The nine subsystems who offer schools through the COMIPEMS are: Universidad Nacional Autónoma de México (UNAM), Instituto Politécnico Nacional (IPN), Universidad Autónoma del Estado de México (UAEM), Colegio Nacional de Educación Profesional Técnica (CONALEP), Colegio de Bachilleres (COLBACH), Dirección General de Educación Tecnológica Industrial (DGETI), Dirección General de Educación Tecnológica Agropecuaria (DGETA), Secretaría de Educación del Gobierno del Estado de México (SE), and Dirección General del Bachillerato (DGB).

${ }^{5}$ The assignment mechanism proceeds as follows. First, the school subsystems report the maximum number of seats available for incoming students. Second, all applicants are ranked by their exam score, from highest to lowest. Third, a computer program scrolls down the ranked list of students, assigning each student to their highest-ranked option with available seats. The process continues until all students are assigned, with the exception of students who did not score enough to enter any of the options they listed. Applicants whose scores are too low to guarantee a seat in any of their preferred schools may be admitted to schools with available seats after the assignment process is over. Alternatively, they can enroll into schools with open admission outside the COMIPEMS system (i.e. private schools or schools outside the COMIPEMS
} 
For our analysis, the assignment mechanism and large maximum number of options suggests that students' listed options are reasonable measures for their underlying preferences over schools.

The Mexican system offers three educational modalities (or tracks) at the upper secondary level: general, technical, and vocational education. The technical modalities include the curriculum covered in a general education program but also incorporate additional courses that allow students to become a technician upon completion of secondary schooling. In turn, a student who choses to receive a vocational education is exclusively trained to become a professional technician. Each school within the COMIPEMS system offers a unique track; in technical and vocational schools, students also choose a specialization. While the system naturally generates ability sorting across schools, sorting across education modalities is less evident in the data. The support of the cutoff distributions for schools offering technical and vocational programs is embedded in the wider support of cutoffs for schools offering academic programs (see Figure A.1 in the Appendix).

\subsection{The Oportunidades Program}

Oportunidades is a conditional cash transfer (CCT) program that targets poor households in Mexico. The program was initiated in 1997 in rural areas, and by 2001 it began to expand into semi-urban and urban areas, reaching the area under study in the second half of 2004. Cash transfers are given on a bimonthly basis to one of the adult household members (usually the mother), and come in two forms. The first is a fixed food stipend which is worth 175 MX\$ (around 16 US\$) per month as from the first half of 2005 and is conditional on family members obtaining preventative medical care. The second is an educational grant which is offered to each household member aged 6-20. To receive the school subsidy, children or youth in participating households must attend school in one of the subsidy-eligible grade levels (grades 3-12) for at least 85 percent of school days. Students who repeat a grade are still eligible for the schooling subsidy, but they cannot receive a subsidy more than twice for the same grade.

Transfers increase with each grade, and are higher for girls than for boys starting from the first grade of secondary school. Average monthly transfer amounts per child by education level are: 163 MX\$ for primary, 355 MX\$ (boys), 393 MX\$ (girls) for lower secondary, and $603 \mathrm{MX} \$$ (boys), $670 \mathrm{MX} \$$ (girls) for upper secondary. In addition, children who are enrolled in school receive an additional monetary transfer for the acquisition of school supplies at the participating municipalities). 
beginning of the academic year (220 MX $\$$ for primary and $275 \mathrm{MX} \$$ for secondary on an annual basis). No household can receive more than 1,055 MX $\$$ per month from a combination of grants for different children. For households with children who are scholarship recipients at the upper secondary level, the transfer is capped at 1,785 $\mathrm{MX} \${ }^{6}$

Although the structure of benefits is identical in rural and urban areas, the procedure by which families become beneficiaries differs. To identify eligible households, program officials visit every household in eligible rural localities and undertake a census, collecting information on a range of household socio-economic characteristics which is used to directly determine entitlement to the program benefits. In urban areas, a comprehensive census is deemed to be too costly, thus an element of self-selection in the registration of beneficiaries is introduced. To determine initial eligibility for the urban program, three general steps are taken: (i) identification of high poverty areas to be served; (ii) information campaigns to promote the program; and (iii) identification of eligible families. If a household visits a program center, information is collected through a household questionnaire and these data are further verified during a home visit. A subset of these characteristics is used to apply a previously developed proxy-means targeting approach. Numerical weights are assigned to human capital and household assets, as well as characteristics of their communities, in order to calculate a household poverty index (score), where a higher score denotes a higher level of poverty [Skoufias et al., 2001].

Oportunidades is a centrally run program. The administrative unit in charge of the program is a federal agency that gathers all the relevant data, applies the points allocation system, determines eligibility, issues payments to households, and coordinates service delivery with other federal ministries and agencies. Hence, there are no intermediaries between the federal government and program beneficiaries. This fact helps to limit the opportunities for political manipulation of the program targeting, whereby, for instance, local politicians may have electoral incentives to strategically change the poverty index of some households in order to expand the coverage of the program [Camacho and Conover, 2011].

\subsection{Sample Description}

We have access to the Oportunidades eligibility survey collected in the second half of 2004 for households living in the town of Ecatepec de Morelos, which is located in the State of

\footnotetext{
${ }^{6}$ During high school, students can further accumulate funds that are redeemable (under certain conditions) upon graduation from high school. For students registered in the program since the last year of lower secondary school, this additional amount is approximately 3,000 MX\$.
} 
Mexico, on the outskirts of Mexico City's Federal District. ${ }^{7}$ While the choice of such specific location is due to data availability constraints, it is important to stress that the municipality of Ecatepec is by and large representative of other municipalities in the Mexico City's area as well as Mexico in general (see Table A.1 in the Appendix).

The Oportunidades dataset contains information on household socio-demographics, the proxy-means score used to determine program eligibility, and the bimonthly record of total cash disbursements from 2005 to 2010. The COMIPEMS dataset features applicants' address of residence, socio-demographic characteristics, past schooling trajectories, the ranked lists of schooling options requested during the application process, and related information about students' placement in the system (including their score in the admission exam). We merge at the individual level these two datasets using student identifiers. ${ }^{8}$ After excluding applicants who lack basic necessary information, we are left with a final sample of 5,232 students who applied in the school assignment system during the period comprised of between 2005 and 2010. Of those, 4,234 (81 percent) were assigned in one of the high school programs offered through the centralized mechanism. Using the same student identifiers, we also match roughly half of the applicants in our sample with individual records in the period comprised of between 2008 and 2013 of the national achievement test of 12th graders, which is carried out in all high schools in Mexico (except those belonging to the UNAM subsystem).

In our sample, 3,180 (61 percent) applicants belong to households that are deemed eligible for the CCT benefits, i.e. the value of their proxy-mean score is greater than or equal to 0.69. Among program eligible students, 2,161 (68 percent) are reported as receiving at least one cash subsidy before applying to the school assignment system, with a median time elapsed between the first program disbursement and the application to the school assignment system of roughly three years. ${ }^{9}$ As a result of the process of program expansion in urban areas that

\footnotetext{
${ }^{7}$ Figure A.2 in the Appendix depicts the geographic location of the municipality of Ecatepec within the Mexico City's area, and the spatial distribution of the schools participating in the school assignment system.

${ }^{8}$ All COMIPEMS applicants have a 16 digit unique student identifier (CURP), that is generated by combining information on student's name, surname, date of birth and state of birth, plus a 2 digit random generated number. All the relevant demographic information is collected by the Oportunidades survey, allowing us to construct a "pseudo-CURP", that only differs from the student identifier in the 2 digit randomly generated number. After removing all the individuals where there is missing information or a "pseudo-CURP" that can be potentially matched with 2 or more CURPs, we are left with a sample of 6,173 applicants in the age group 14-20.

${ }^{9}$ Program take-up rates are fairly high when compared with the corresponding figures reported in the existing evaluation studies of the urban component of Oportunidades [Angelucci and Attanasio, 2009]. Previous studies use the urban evaluation surveys (ENCELURB) which entail roughly 18-24 months between program inception and observed outcomes, whereas we observe eligible households for up to six years after program inception. In fact, take-up rates in our sample increase from 40 percent in 2005 to 79 percent in 2010.
} 
took place in the end of 2008, a very small fraction (1.2 percent) of ineligible applicants in our sample are reported as receiving some program benefits before applying to the schooling system. For the median household in our sample, the Oportunidades transfer is between 27 and 28 percent of total household income. The large size of the income shock in our sample likely reflects the presence of program-eligible household members who are attending high school (for whom the schooling subsidy is higher, see Section 2.2). In fact, the transfer amount for program eligible families who reside in the city of Ecatepec de Morelos and who are not in the COMIPEMS sample are substantially lower, that is, between 14 and 16 percent of total household income for the median household in our sample. Those figures are in line with previous studies that considered the urban component of the Oportunidades program [Angelucci and Attanasio, 2013].

Using the school identifiers, we further link the applicants' stated school preferences and assignment with the biannual Mexican school census, which collects information on schoollevel yearly trajectories, e.g. enrollment, failure rate, etc, school infrastructure, as well as detailed information on the attendance fees that students have to incur upon registration in a given school (e.g. tools, uniforms, monthly payments, registration, and tuition). In addition, geocoded information for each school allows us to compute geodesic distances between students' places of residence and the high school programs offered by the school assignment system.

\subsection{High School Track Choices}

Only 9 percent of the applicants in our sample list a vocational program as their first option, while 44 percent and 47 percent of the applicants, respectively, opt for the technical and the general tracks. Among those who choose a technical program, almost 40 percent choose a program that covers mixed (and presumably, more general) specializations, as opposed to the vocational track where the most preferred programs seem to be geared toward the acquisition of rather specific labor market skills (see Figure A.3 in the Appendix). When compared to students who opt for general and technical tracks, those who mostly prefer a vocational education tend to perform worse in school (the mean differences in the score in the admission exam and in the cumulative grade point average in lower secondary are 0.44 of a standard deviation and 0.32 of a standard deviation, respectively), and tend to come from a more disadvantaged socio-economic background (mean differences in household income and mother education are 0.15 of a standard deviation and 0.12 of a standard deviation, respectively). 
An education reform carried out in 2008 allowed students graduating from the vocational track to attend higher education, although graduates from the general track remain more likely to enroll in tertiary schooling when compared to graduates from the other tracks (33 percent more than technical, and 38 percent than vocational). ${ }^{10}$ However, the share of low income students who enter higher education in Mexico is extremely low: in 2013 students coming from the lowest household income quintile, which includes most of the Oportunidades beneficiaries, made up only 10.6 percent of the total higher education enrollment [Ferreyra et al., 2017]. When we look at the labor market returns of the different high school tracks among those individuals who enter the labor market upon high school graduation, we find that log hourly wages are on average 14 and 7 percent larger for vocational high school graduates when compared to high school graduates from the general and technical tracks, respectively. ${ }^{11}$ These figures may be possibly affected by selection issues whereby individuals who choose not to attend or complete college after graduating from the general or technical tracks are difficult to compare with those who graduate from the vocational track. However, it is not clear whether students rely on conditional or unconditional market returns when choosing their schooling curriculum. Indeed, subjective expectation data on labor market earnings for a nationally representative sample of high school students are broadly consistent with the observed market returns (see Figure A.4 in the Appendix).

The evidence presented above makes it difficult to understand why students from low income households disproportionally privilege academically-oriented high school curriculums. One possible explanation can be found in the relatively higher costs of the vocational options. The more frequent use of computers and laboratory equipment in the vocational curriculum may partly explain the fact that vocational schools face higher running costs and they tend to charge higher attendance fees while being less geographically accessible for relatively disadvantaged households when compared to technical and academic options. ${ }^{12}$ Table 1 shows, separately for each high school track, the mean and standard deviations of total attendance fees and the geodesic distance from the residential locations for a sub-set of COMIPEMS schools that are likely to be the most relevant for the school choices of the

\footnotetext{
${ }^{10}$ Data from a nationally representative survey of high-school graduates aged 18-20 (ENILEMS, 2012).

${ }^{11}$ We estimate mincer-type regressions using data from a sub-module of the national employment survey (ENTELEMS-ENOE, 2008), which records wages and hours worked as well as retrospective information on academic trajectories for individuals aged 16-35 (see Table A.2 in the Appendix). The specifications further include dummies for age, gender, urban/rural residence and State of residence. The positive returns to vocational high schools do not vary systematically along any of these observable characteristics.

${ }^{12}$ Amongst all COMIPEMS schools in the year 2007, the number of student per personal computer is 22.5 in the general track and 6.8 in the vocational, while the number of laboratory classrooms is 2.16 and 3.6, respectively. The average yearly attendance fees for vocational programs amounts to 4,195 MX\$ (around $315 \mathrm{US} \$$ ) as opposed to $2,794 \mathrm{MX} \$$ for technical programs costs and 3,772 MX\$ for academic programs.
} 
applicants in our sample. The average attendance cost for the vocational programs that are most closely located from the students' places of residence is 4,700 MX $\$$ (around 350 US\$), which roughly corresponds to 15 percent of the median household income in our sample, compared to 3,980 MX\$ and 2,390 MX\$ for the closest general and technical schools, respectively. In addition, the closest general and technical schools are located, on average, 1 $\mathrm{km}$ and $2 \mathrm{~km}$ away, respectively, whereas the closest vocational school is located $3.3 \mathrm{~km}$ away from the applicants' residences (see Panel A). Similar patterns hold when we alternatively consider the 10 nearest options in each high school track (see Panel B).

Table 1: Schooling Costs Across High-School Tracks

\begin{tabular}{lccc}
\hline \hline & $(1)$ & $(2)$ & $(3)$ \\
& General & Technical & Vocational \\
Panel A: Nearest schools by track & & & \\
\hline Attendance Fees (MX\$) & 3,981 & 2,388 & 4,699 \\
& $(1,784)$ & $(1,242)$ & $(1,086)$ \\
Geodesic Distance (Km) & 1.26 & 2.01 & 3.25 \\
& $(0.98)$ & $(1.22)$ & $(1.77)$ \\
Panel B: Ten nearest schools by track & & \\
\hline Average Attendance Fees (MX\$) & 3,629 & 2,934 & 4,516 \\
& $(547.9)$ & $(614.5)$ & $(368.2)$ \\
Average Geodesic Distance (Km) & 3.88 & 5.75 & 8.78 \\
& $(1.19)$ & $(1.13)$ & $(2.23)$ \\
\hline \hline
\end{tabular}

Notes: Nearest schools selected using the geodesic distance between the location of the applicants' residences and the locations of all the COMIPEMS schools. Means and standard deviations (in parenthesis) computed over the applicants in our sample. All mean differences between tracks are statistically significant at the 1 percent level. Total attendance fees refer to the year 2009 (current exchange rate MX\$/US\$=13.33) and include tools, uniforms, monthly payments, registration and tuition. Sources: National Institute of Statistics and Geography (INEGI), and school census (Formato 911).

Relative to the other tracks, the vocational curriculum can thus be possibly associated with higher labor market returns for students in relatively poor households, while at the same time entails higher out-of-pocket expenditures. 


\section{Empirical Strategy}

\subsection{A (Fuzzy) Regression Discontinuity Design}

The eligibility for the transfer program depends solely on whether or not the household poverty score exceeds a fixed cutoff, that is time invariant during the period under study and unknown by potential beneficiaries. Let $X_{i}$ denote the household eligibility score, $c$ the cutoff value of eligibility, and $Z_{i}$ a program treatment indicator. In order to account for the non-perfect compliance with the transfer program (see Sections 2.2-2.3), we consider the following linear regression model:

$$
\begin{aligned}
Z_{i} & =\alpha_{0}+\alpha_{1} \mathbf{1}\left(X_{i}>c\right)+\alpha_{2} f\left(X_{i}-c\right)+\epsilon_{i}, \\
Y_{i} & =\gamma_{0}+\gamma_{1} Z_{i}+\gamma_{2} f\left(X_{i}-c\right)+\eta_{i},
\end{aligned}
$$

where $\gamma_{1}$ is the local average treatment effect (LATE) of Oportunidades transfers on track choice. $\epsilon_{i}$ and $\eta_{i}$ are mean zero error terms, which are clustered by values of the poverty score [Lee and Card, 2008]. ${ }^{13}$ The term $\left(X_{i}-c\right)$ accounts for the influence of the running variable on both track choices and program assignment in a flexible nonlinear function $f(\cdot)$, which is allowed to vary above and below the threshold. Analogously, we can express the reduced-form relationship between program benefits and track choice as following:

$$
Y_{i}=\beta_{0}+\beta_{1} \mathbf{1}\left(X_{i}>c\right)+\beta_{2} f\left(X_{i}-c\right)+u_{i}
$$

where $\beta_{1}$ is the intention-to-treat (ITT) effect of the eligibility for the transfer program on track choice and $u_{i}$ is a mean zero error term. Ideally, we would like to estimate both ITT and LATE parameters in the neighborhood of the program eligibility threshold $c$. Given our sample size, the number of observations around the threshold might be relatively small and thereby may potentially compromise the resulting estimates [Lee and Lemieux, 2010]. Thus, in our main specifications we use a parametric functional form that exploits the entire sample. One potential disadvantage of the parametric approach is the bias produced by individuals who are located further away from the cutoff when $f(\cdot)$ is not correctly specified. For this reason, we complement our results showing the corresponding ITT and LATE estimates of Local Linear Regression (LLR) models that restrict the sample to the observations around

\footnotetext{
${ }^{13}$ The poverty score is approximated at the third decimal digit, which implies a few repeated observations at some specific values. Estimation results (available upon request) are very similar when we instead use heteroskedasticity-robust standard errors.
} 
the score eligibility cutoff.

In order to interpret the likelihood of receiving the program benefits as the result of a local randomization in a neighborhood of the eligibility cutoff, the probability of receiving the Oportunidades benefits needs to change discontinuously at the eligibility cutoff and the assignment variable has to be continuously distributed around the eligibility cutoff. The latter assumption is akin to assuming that households cannot precisely manipulate the poverty score in order to be eligible for the transfer [Lee, 2008]. Two additional assumptions are needed for (non-parametric) identification of the LATE parameter in Equations (1)-(2) [Hahn et al., 2001]: monotonicity of the treatment assignment; and scoring above threshold cannot impact track choices except through the effect of the transfer (exclusion restriction). To our knowledge, in the context under study there are no other government-sponsored programs that use the same poverty score and its related assignment rule. In the next section, we discuss the plausibility of these assumptions in our sample.

\subsection{Validity of the RD Design}

We start by assessing the empirical density of the assignment variable around the cutoff of program eligibility. Martinelli and Parker [2009] find evidence that households tend to under-report goods and desirable home characteristics in order to increase the chances of being eligible for the Oportunidades program. In the absence of perfect monitoring of the self-reported information, we might thus observe a discrete jump in the distribution of the household poverty score immediately above the eligibility threshold, thereby suggesting that households can manipulate the assignment variable. Using all households in our sample with at least one child in the COMIPEMS exam we can inspect the presence of a discontinuity in the assignment variable at the cutoff of program eligibility (see Figure 1).

There is no evidence that in the population under study, households are manipulating the score in order to increase the probability of being eligible for the transfer. Instead, visual inspection reveals the presence of a small drop (rather than a bump) immediately above the eligibility cutoff. The point estimate of the log difference in height between the two interpolating kernel regressions is -0.134 (std. err.=0.074). This pattern is consistent with the fact that after the initial targeting procedures are completed (see Section 2.2), internal audits are conducted in order to verify whether or not potential recipients truly meet the eligibility requirements. These audits led to administrative corrections that eventually

resulted in program exclusion for some households who were initially claimed eligible to receive the program benefits. 
Figure 1: Density of the Program Eligibility Score

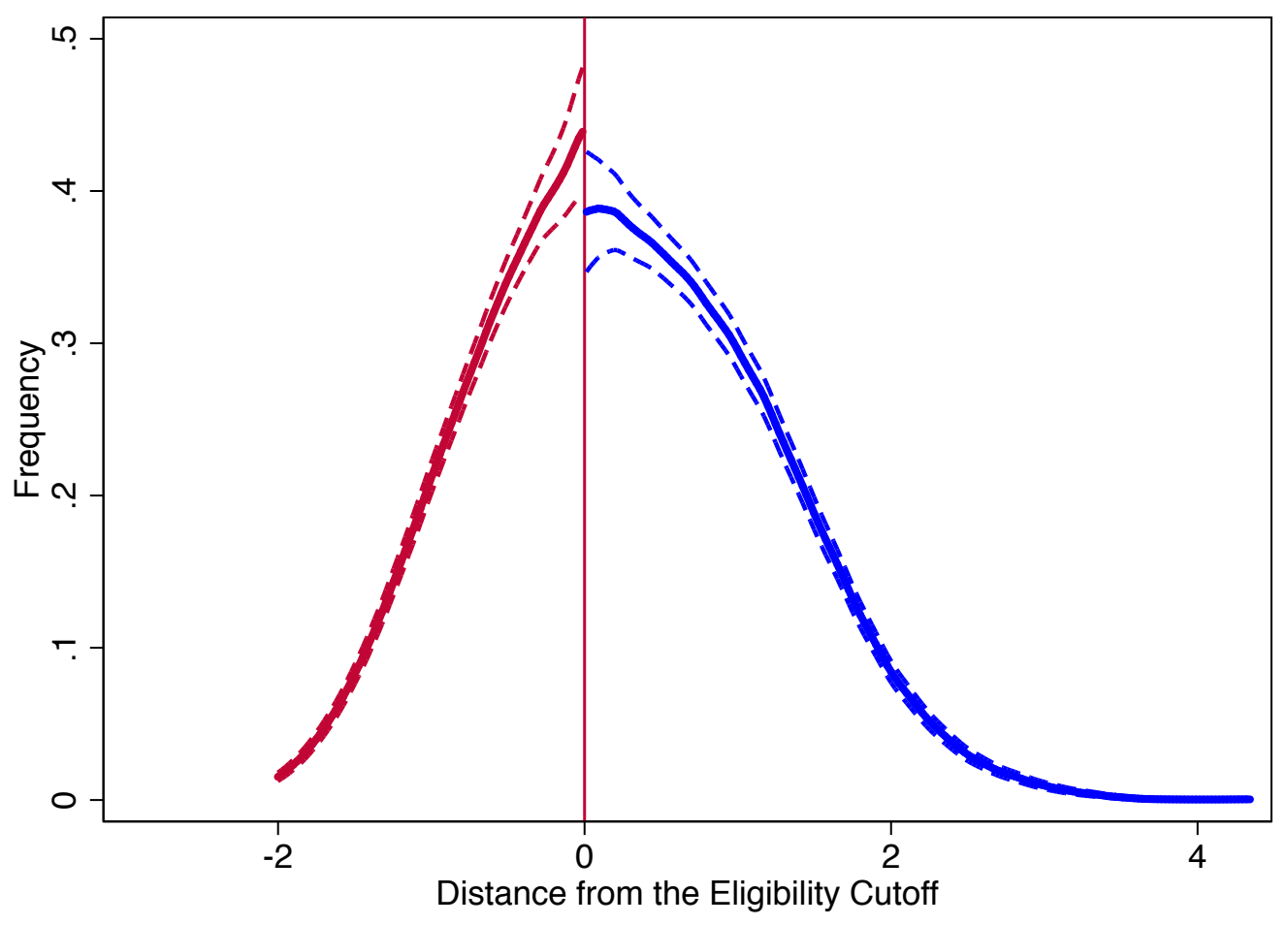

Note: This figure depicts a kernel regression interpolation and the confidence intervals of the empirical distribution of the assignment variable at the points below and above the cutoff. The bin size and the optimal bandwidth are calculated using the procedure described in McCrary [2008].

Figure 2 displays the relationship between the poverty score (x-axis) and a set of sociodemographic characteristics collected in the 2004 program eligibility survey (y-axis): applicants' age and ethnicity; school enrollment and attainment for all children in the applicants' households and households size; and level of parental education. The charts do not reveal the presence of any discrete jump around the eligibility cutoff for these variables. A battery of statistical tests largely confirm these visual patterns, providing further support to the notion that households are unlikely to sort around the program eligibility cutoff in our setting. ${ }^{14}$

The graph presented in panel (a) of Figure 3 (see Section 4.1) shows clear evidence of a discontinuous change in the probability of taking the cash transfer at the eligibility cut-

\footnotetext{
${ }^{14}$ The corresponding regression estimates for the full set of available pre-program socio-demographic characteristics are reported in Table B.1 in the Appendix. A cross-equation test based on a seemingly-unrelated regression (SURE) model delivers a Chi-squared statistic of 7.93 (p-value=0.719). The ITT coefficient for the predicted values of a Multinomial Logit regression of the choice of vocational/technical/general tracks as first options on the full set of socio-demographic characteristics has a point estimate of -.00021 (std. err $=0.0016$ ). A permutation test based on the induced ordered statistics for the null hypothesis of continuity of the distribution of baseline covariates at the cutoff [Canay and Kamat, 2015] delivers a p-value of 0.234.
} 
Figure 2: Covariate Smoothness: Graphical Evidence



(a) Age

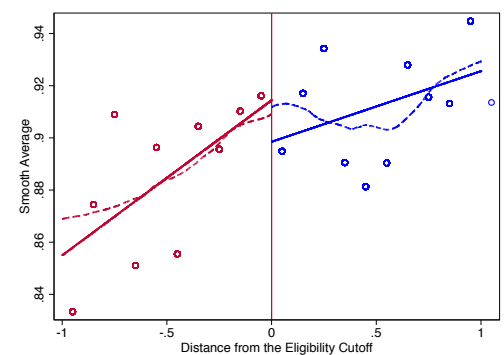

(d) Share of Children in School

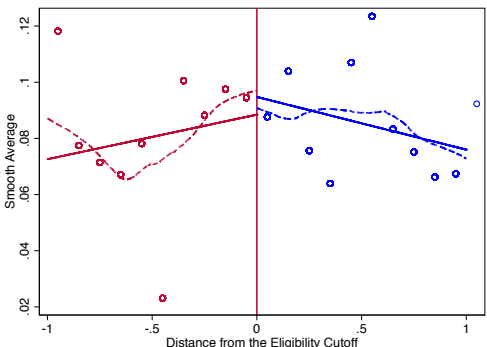

(b) Ethnicity (1 indigenous)

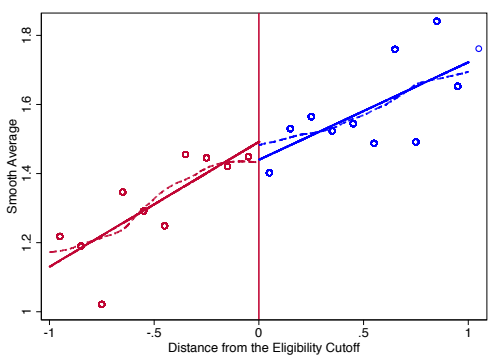

(e) \# Children with Prim. Educ

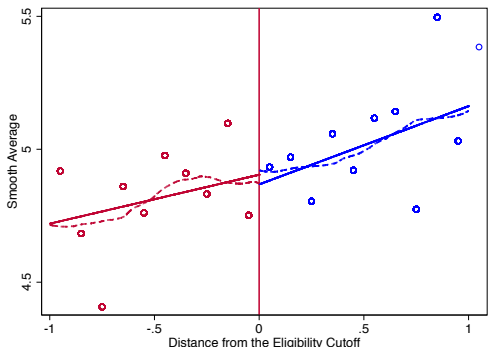

(c) \# of $\mathrm{HH}$ members



(f) \# Children with Sec. Educ.

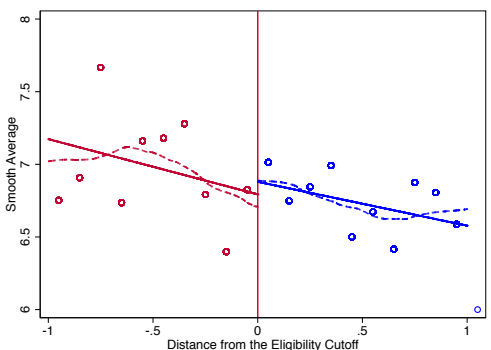

(g) HH Head Education (years)

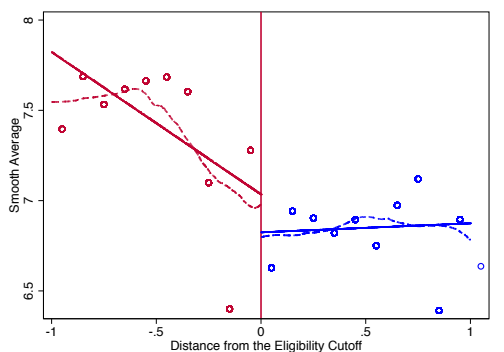

(h) HH Spouse Education (years)

NotE: The figure plots averages of the dependent variable computed over 0.10 consecutive brackets values of the poverty score comprised between -1 and 1, which roughly entails 70 percent of the overall sample of COMIPEMS applicants. The red vertical line denotes the discontinuity, normalized to zero. The solid line (dashed line) is a local linear regression prediction (least squares running-mean smoothing), separated on either side of the threshold.

off. The probability of taking the transfer is remarkably flat for those households where the poverty score is above the eligibility threshold, and this provides some support for the monotonicity assumption of the treatment assignment. A potential violation might have occurred if the cost of complying with the program conditionality had increased with the poverty score, thereby decreasing the likelihood to receive the program benefits for households in the neighborhood of the eligibility cutoff. Neither previous work on Oportunidades in urban areas [Gonzalez-Flores et al., 2012] nor the results presented here tend to support 
this hypothesis.

One potential concern regarding our research design is that the eligibility for the Oportunidades cash transfer may have changed the composition of the COMIPEMS applicants by, for instance, inducing lower-ability students to take part in the school assignment system. ${ }^{15}$ In order to address this concern, we estimate Equation 3 so as to assess the impact of the program eligibility on the probability of taking part in the COMIPEMS system. We compute such probability in our data by restricting the potential population of applicants in the 2004 Oportunidades eligibility survey to those who are currently enrolled in school and whose age matches that of subsequent cohorts of high school applicants over the period 2005-2010 (9-14 years old). ${ }^{16}$ We also use two additional measures of the academic ability of the pool of applicants in our sample: the score in the assignment exam; and the overall GPA in middle school, as well as the geodesic distance between the closest vocational school and applicants' residence. The estimated ITT effect of cash transfers on these outcomes are small in magnitude and not statistically different from zero (see Table B.2 in the Appendix), thereby lending further support to the view that the observed changes in students' preferences across tracks are not the result of changes in the composition of the sample under study.

\section{RD Estimates on Track Choices}

\subsection{Graphical Analysis}

We first conduct a graphical analysis in order to document the discontinuity effects of the program transfers on the likelihood of choosing one of the three educational tracks (vocational, technical and academic) as a first option within the COMIPEMS school assignment system. Jumps in the plots depicted in Figure 3 show the effect of crossing the threshold on the variables of interest. The impact of the transfer on track choices can then be assessed visually by inspecting the ratio of the jump in terms of the probability of choosing a given track, and the jump in the probability of receiving the transfer (panel (a)). The graphical

\footnotetext{
${ }^{15}$ Another potential source of selection can be triggered by the positive effect of Oportunidades on migration [Angelucci, 2015]. If higher (lower) ability students are more likely to migrate out of the Mexico City metropolitan area upon receiving the transfer, the sample of the high school applicants might potentially display a negative (positive) selection bias.

${ }^{16}$ The resulting matching rate between the two datasets is 42 percent, which can be explained by potential mismatches in the CURPs, non-universal completion in lower secondary (91 percent in the school year 20132014), the rate of absorption into upper secondary (93.6 percent in the same school year), and high school enrollment outside of the COMIPEMS schools (roughly 30 percent).
} 
evidence appears to show the presence of a positive effect of the receipt of Oportunidades on the probability of choosing a high school program belonging to the vocational track (panel (b)). Accordingly, the transfers appear to be associated with a decrease in the probability of choosing the technical or the academic tracks, with a possibly more pronounced effect for the former, although no clear pattern emerges from visual inspection of panels (c) and (d) of Figure 3.

Besides, away from a close neighborhood of the discontinuity there is a clear declining trend in the probability of choosing the vocational track as the poverty score increases, whereas, again, no clear trend emerges for the other two tracks. This provides further (suggestive) evidence for the potential role of liquidity constraints underlying the choice of a vocational program.

\subsection{Regression Analysis}

In Table 2 we present statistical evidence for the estimation of the $\beta_{1}$ and $\gamma_{1}$ coefficients of Equations (1), (2) and (3) using simple linear probability models for each track as first option. We use a quadratic spline in the poverty score in order to control for the influence of the running variable on both track choices and program assignment. We further include application-year dummies in all specifications in order to account for potentially different trends across the cohorts of applicants in our sample.

The estimated marginal effect of the program eligibility on the probability of choosing the vocational track is 4 percentage points, and is statistically significant at 5 percent level (column 1). When we account for the imperfect compliance with the Oportunidades transfer, we find that the corresponding LATE is equal to 6.2 percentage points. Compared with the 9.2 percent baseline probability of choosing the vocational track as first option, the relative magnitude of this effect is definitely sizable. The effects of the program on the probability of choosing the academic track as first option are small in magnitude and they are not statistically significant (column 2). The probability of choosing the technical track as first option shows a drop that is comparable in magnitude with the positive effects observed for the vocational track, although the estimated coefficients are not statistically different from zero. $^{17}$

We next consider three specification checks. First, we examine the robustness of our

\footnotetext{
${ }^{17}$ The lack of statistical significance for the estimated coefficients in column 3 of Table 2 is arguably related to the relatively small size of our sample. In fact, the standard deviation of the dependent variable nearly doubles in column 3 , so that the minimum effect that can be statistically detected at conventional significance levels is much larger.
} 
Figure 3: Discontinuity Effects of Program Eligibility on Track Choice

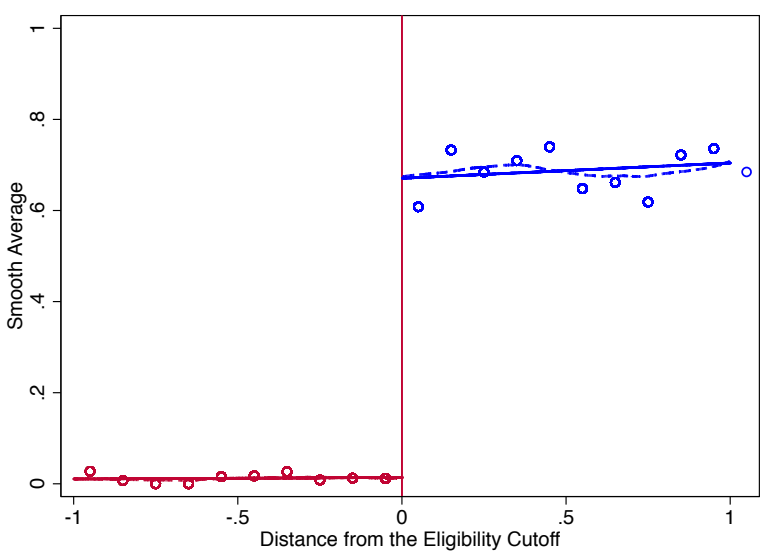

(a) Program Take-up

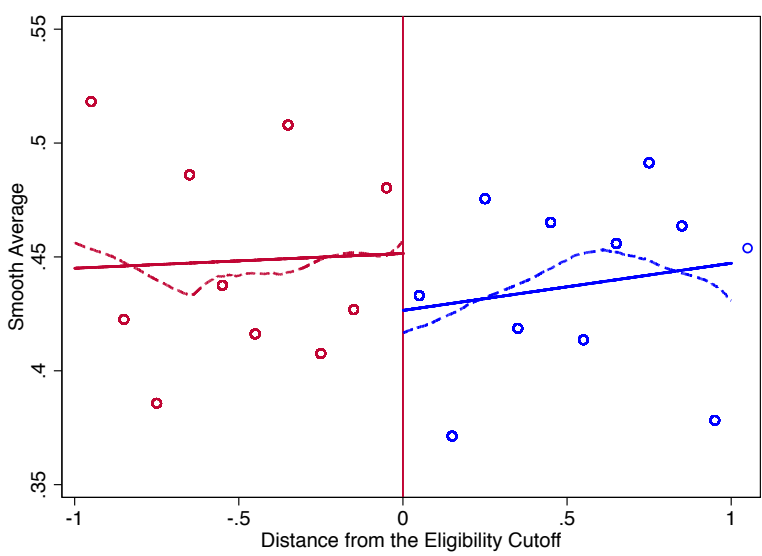

(c) Technical Track (1st option)

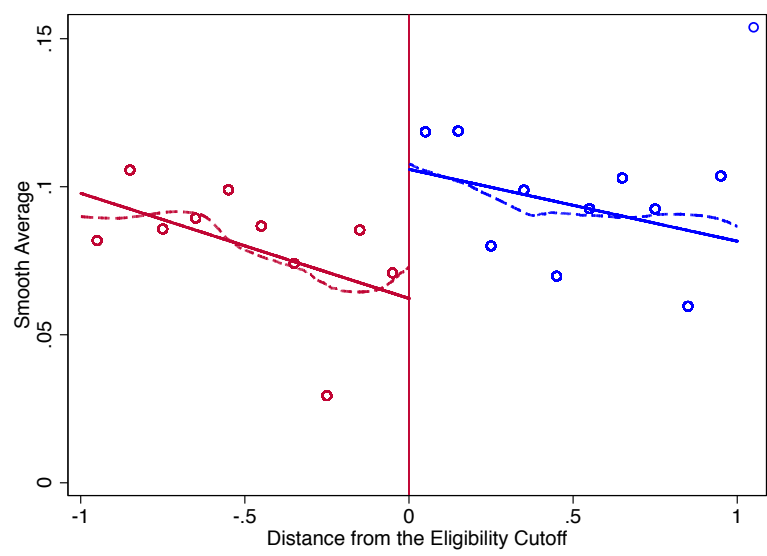

(b) Vocational Track (1st option)

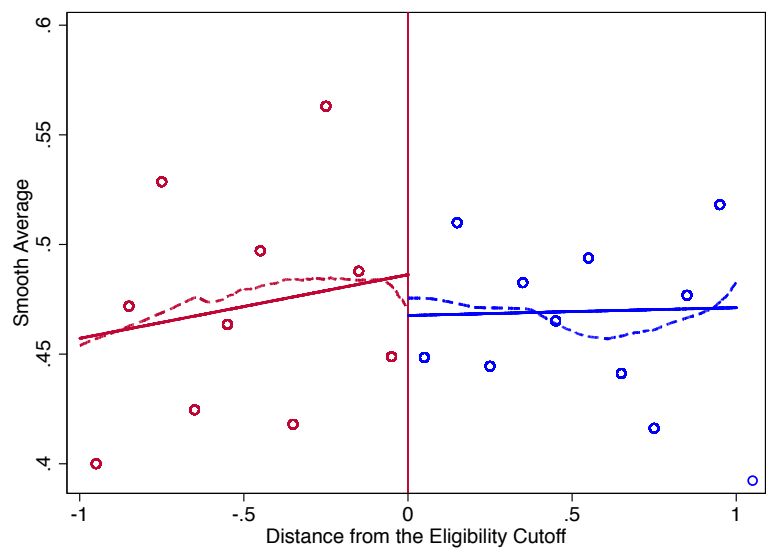

(d) Academic Track (1st option)

Note: The figure plots averages of the dependent variable computed over 0.10 consecutive brackets values of the poverty score comprised between -1 and 1 , which roughly entails 70 percent of the overall sample of COMIPEMS applicants. The solid line (dashed line) is a local linear regression prediction (least squares running-mean smoothing), separated on either side of the threshold.

findings by choosing different degrees of the polynomial that is supposed to control for the direct influence of the poverty score on both track choices and program assignment. Second, we fit local linear regression models for a subset of the observations that are in the neighborhood of the eligibility cutoff, as determined using the optimal bandwidth criterion as in Imbens and Kalyanaraman [2012]. Third, we consider the joint decision on the preferred track within the school assignment system using a Multinomial Logit model that we estimate using both parametric specifications described above. The resulting estimates are displayed in Tables C.1, C.2, C.3 and are remarkably consistent in both significance and magnitude 
Table 2: The Effects of Cash Transfers on Track Choices

\begin{tabular}{|c|c|c|c|}
\hline & $\begin{array}{c}\text { Vocational } \\
(1)\end{array}$ & $\begin{array}{c}\text { General } \\
(2)\end{array}$ & $\begin{array}{c}\text { Technical } \\
(3)\end{array}$ \\
\hline \multicolumn{4}{|l|}{$O L S(I T T)$} \\
\hline Score $>$ Cutoff (1 yes) & $\begin{array}{c}0.040^{* *} \\
(0.019)\end{array}$ & $\begin{array}{c}0.013 \\
(0.037)\end{array}$ & $\begin{array}{l}-0.053 \\
(0.036)\end{array}$ \\
\hline \multicolumn{4}{|l|}{ 2SLS (IV-LATE) } \\
\hline Takeup & $\begin{array}{c}0.062^{* *} \\
(0.030)\end{array}$ & $\begin{array}{c}0.020 \\
(0.057) \\
\end{array}$ & $\begin{array}{l}-0.082 \\
(0.056) \\
\end{array}$ \\
\hline Mean Dependent Variable & 0.092 & 0.465 & 0.443 \\
\hline SD Dependent Variable & 0.289 & 0.499 & 0.497 \\
\hline Number of Observations & 5,232 & 5,232 & 5,232 \\
\hline Number of Clusters & 2,907 & 2,907 & 2,907 \\
\hline \multicolumn{4}{|c|}{$\begin{array}{l}\text { Note: } * \text { significant at } 10 \% \text {; } * * \text { significant at } 5 \% \text {. The dependent } \\
\text { variable Vocational/General/Technical takes the value } 1 \text { if a Voca- } \\
\text { tional/General/Technical option is listed first in the applicant's portfolio. } \\
\text { A quadratic spline specification for the poverty score is used at each side } \\
\text { of the cutoff. Standard errors clustered by values of the poverty score } \\
\text { are reported in parenthesis. Application-year dummies are included in all } \\
\text { specifications. }\end{array}$} \\
\hline
\end{tabular}

with those just discussed. If anything, the estimated coefficients are slightly larger, e.g. the LATE of the cash transfer on the probability of selecting a vocational option as first choice is equal to 7 percentage points.

\subsection{Mechanisms}

The cash transfer provided with the Oportunidades program may tilt school choices toward the vocational track though either an income effect or a price effect - i.e. by reducing the need to borrow at a high rate to finance the preferred schooling career. While both channels may be at play, we cannot empirically distinguish them and hence we interpret the effects of the cash transfers on track choice decisions as broadly relaxing households' liquidity constraints. ${ }^{18}$

In our setting, relatively low ability students are those who are expected to benefit more

\footnotetext{
${ }^{18}$ The conditional component of the transfer may possibly generates another price effect by effectively reducing the shadow value of schooling. This channel should mainly affect schooling decisions at the extensive margin - i.e. high school enrollment and attendance - rather than the intensive margin, which is the object of interest of our analysis.
} 
from a schooling career that prepares them to access the labor market (see Section 2.4) as they are less likely to continue their studies toward tertiary education. ${ }^{19}$ We use information on the overall Grade Point Average (GPA) in lower secondary, and accordingly classify as high-ability and low-ability those students with GPA above and below the mean respectively. We then estimate Equations (1) and (2) by allowing the corresponding LATE to vary with the level of ability, and we report the results in column 1 of Table 3. For students with a high GPA, the effect of the cash transfer on the probability of choosing the vocational track as first option is small and is not statistically significant from zero, as opposed to a large and statistically significant effect (11.4 percentage points) for those with a low GPA.

Transportation costs may constrain schooling decisions, especially for low income families. Using information on the distance from each applicants' residence to the closest vocational option as a proxy for the transportation cost that they have to incur in order to attend a vocational program, we estimate how the LATE varies for students who are below or above the mean distance in the sample. These results are reported in column 2 of Table 3 . The size of the estimated coefficient is large (6.8 percentage points) and statistically significant for higher-distance students, while it is smaller and not statistically significant for lowerdistance students. Consistently with the evidence reported in column 1, these heterogenous track choice responses are more pronounced for students with a low GPA (column 3) whereas they are indistinguishable both from each others and from zero among students with a high GPA (column 4). As before, we check and verify the robustness of these results using two alternative specifications for estimating the LATE parameter: cubic splines (Table C.4) and local linear regressions (Table C.5).

Unconditionally on the track chosen, if the receipt of the cash transfer weakens the household liquidity constraints, then we would expect students to choose more expensive schooling options, for instance, in terms of attendance and transportation costs. Results based on the estimation of Equations 1 and 2 using both parametric and non-parametric specifications are reported in Table 4. The LATE of the cash transfer program is positive and significant on the attendance cost associated with the preferred option solicited by the applicants in our sample, with a magnitude in a range comprised between 290 and 344 MX \$ depending on the specification, which corresponds roughly to 13-15 percent of the sample mean of attendance costs for the most preferred schooling options. The LATE on the geodesic

\footnotetext{
${ }^{19}$ Higher ability students are also more likely be less financially constrained due to higher access to meritbased scholarship at the upper secondary level. For instance, students whose COMIPEMS score are high enough to enter UNAM options are provided with direct access to university programs of the same institution - among the best ones in the country - and are automatically granted a scholarship that covers most of the school-related expenses both at secondary and tertiary level.
} 
Table 3: Heterogeneous LATE on Vocational Choice

\begin{tabular}{lcccc}
\hline \hline Sample & $(1)$ & $(2)$ & $(3)$ & $(4)$ \\
& All & All & Low GPA & High GPA \\
\hline Takeup $\times$ Low GPA & $0.114^{* * *}$ & & & \\
Takeup $\times$ High GPA & $(0.032)$ & & & \\
& 0.003 & & & \\
Takeup $\times$ Low Distance & $(0.030)$ & & & \\
& & & & \\
Takeup $\times$ High Distance & & 0.045 & 0.063 & 0.036 \\
& & $0.068^{* *}$ & $(0.051)$ & $(0.039)$ \\
\hline P value: Takeup $\times$ _low=Takeup $\times$ high & 0.000 & $0.141^{* *}$ & 0.039 \\
Observations & 5232 & 5232 & 2443 & 2789 \\
Clusters & 2907 & 2907 & 1739 & 1916 \\
\hline \hline
\end{tabular}

Note: * significant at $10 \%$; ${ }^{*}$ significant at $5 \%$; *** significant at $1 \%$. 2SLS estimates (quadratic spline specification for the eligibility score). Standard errors clustered by values of the poverty score are reported in parenthesis. High and Low GPA students are those with the overall Grade Point Average (GPA) in lower secondary above and below the mean respectively. High and Low Distance students are those whose distance from the close vocational option is above and below the mean respectively.

distance between the location of the preferred schooling option and applicants' residence is also positive and sizable in magnitude, although it is significantly different from zero in only one of the four different specifications (column 3).

\subsection{Alternative Mechanisms}

As described in Section 2.2, Oportunidades cash transfers are conditional on health and schooling behaviors. Although there is no component of the transfer that is directly linked to the high school track attended, we can not a priori rule out the possibility that our results are the outcome of the conditional nature of the transfer. The requirement that each eligible child has to be enrolled in school for receiving the scholarship component of the transfer and that she cannot receive the transfer more than twice for the same grade may potentially have a direct effect on school choices. For instance, students may strategically select relatively easier schools so as to increase their chances of gaining admission, passing grades and receiving Oportunidades scholarships up until the end of upper secondary.

We use Equation (3) to test whether or not the eligibility for the cash transfer has an 
Table 4: The Effects of Cash Transfers on the Schooling Costs of the First Choice

\begin{tabular}{|c|c|c|c|c|}
\hline & $\begin{array}{c}(1) \\
\text { Quadratic Spline }\end{array}$ & $\begin{array}{c}(2) \\
\text { Cubic Spline }\end{array}$ & $\begin{array}{c}(3) \\
\text { LLR-1BW }\end{array}$ & $\begin{array}{c}(4) \\
\text { LLR-0.5BW }\end{array}$ \\
\hline \multicolumn{5}{|c|}{ Dependent Variable: Yearly Attendance Fees (MX\$) } \\
\hline Takeup & $\begin{array}{c}290.081^{* *} \\
(138.614)\end{array}$ & $\begin{array}{l}285.782^{*} \\
(169.271)\end{array}$ & $\begin{array}{l}343.750^{*} \\
(188.126)\end{array}$ & $\begin{array}{c}339.498 \\
(280.991)\end{array}$ \\
\hline Mean Dep. Var. & 2,234 & 2,234 & 2,171 & 2,109 \\
\hline Observations & 5232 & 5232 & 2852 & 1496 \\
\hline Clusters & 2907 & 2907 & 1498 & 762 \\
\hline \multicolumn{5}{|c|}{ Dependent Variable: Geodesic Distance (Km) Between School and Residence } \\
\hline Takeup & $\begin{array}{c}0.686 \\
(0.690)\end{array}$ & $\begin{array}{c}1.000 \\
(0.865)\end{array}$ & $\begin{array}{l}2.264^{* *} \\
(1.130)\end{array}$ & $\begin{array}{c}2.842 \\
(1.921)\end{array}$ \\
\hline Mean Dep. Var. & 7.49 & 7.49 & 7.61 & 7.71 \\
\hline Observations & 5232 & 5232 & 2075 & 1072 \\
\hline Clusters & 2907 & 2907 & 1073 & 553 \\
\hline
\end{tabular}

Note: $*$ significant at $10 \%$; $*$ significant at $5 \%$. Total attendance fees include tools, uniforms, monthly payments, registration and tuition. 2SLS estimates in columns 1 and 2. Local Linear 2SLS estimates using the triangular Kernel in columns 3 and 4 . The bandwidth is chosen according to the optimal criterion in Imbens and Kalyanaraman [2012]. Standard errors clustered by values of the eligibility score are reported in parenthesis. Applicationyear dummies are included in all specifications.

impact on the level of selectivity and/or difficulty of the most preferred high school option in the application portfolios of the students in our sample. Given the assignment algorithm (see Section 2.1), one plausibly good proxy measure for the expected probability of admission in a given school is the corresponding cutoff score in the admission exam in the previous year. ${ }^{20}$ Regression results reported in the top panel of Table 5 show that, irrespective of the specification, the impact of the eligibility to the cash transfers on the cutoff score of the first option requested in the school assignment system is small and not statistically significant from zero. We next employ two measures of school difficulty. First, the school-average performance amongst 12th graders in a national standardized achievement test in 2008 in both language and math. Second, the school-level June pass rates in the academic year 2005-

\footnotetext{
${ }^{20}$ Since 2005 , past cutoff scores for each schooling option have been made available through the COMIPEMS website. This site is frequently checked by the applicants as it has become the main channel to pre-register and is also a key source of additional information about the system.
} 
2006. The corresponding estimates are reported in the bottom panels of Table 5, and mostly reveal no effects of the eligibility to the Oportunidades cash transfer within those margins. ${ }^{21}$ Overall, we interpret these results as evidence that the findings discussed above are unlikely to be directly or indirectly related to the compliance to the program conditionality among children in program eligible households.

By relaxing the household financial constraints, the Oportunidades cash transfers have been found to increase entry into entrepreneurship of the beneficiary parents [Bianchi and Bobba, 2013]. Hence, an indirect channel through which the program may have tilted high school track choices toward vocational options is through parental occupation choices. We test this hypothesis using information on the occupational categories included in the COMIPEMS application surveys and constructing indicator variables for whether or not either the father or the mother of the students in our sample are self-employed. Table 6 reports the corresponding ITT estimates. Results show that they are positive for fathers and negative for mothers but, once again, they are small in magnitude and not statistically different from zero.

\section{$5 \quad$ RD Estimates on Schooling Trajectories}

\subsection{School Assignment}

We first establish empirically whether or not the observed change in preferences over tracks triggered by the cash transfer affects admission outcomes within the school assignment system. On average, technical options display lower attendance and transportation costs than vocational ones (see Table 1), but they also require higher scores in the admission exam (see Figure A.1 in the Appendix). Therefore, more financially constrained students might de facto reduce the probability of being assigned to their first option in the attempt to pursue a more affordable one. For this purpose, we study whether or not the cash transfers provided by the program increase the probability of being assigned to the first solicited option. The estimated LATE is reported in the column 1 of Table 7 and shows a 7.8 percentage point increase, which is statistically significant at the 10 percent level. This is a large effect, as it corresponds to roughly one quarter of the average probability of assignment in the first solicited option in the sample.

We next study whether or not measures of ability and liquidity constraints can shape the

\footnotetext{
${ }^{21} \mathrm{~A}$ few ITT effects reported in Table 5 appear statistically significant in some specifications (negative for the 12th grade score and positive for the pass rate).
} 
Table 5: Measures of School Selectivity/Difficulty of the First Choice

\begin{tabular}{|c|c|c|c|c|}
\hline & $\begin{array}{c}\text { (1) } \\
\text { Quadratic Spline }\end{array}$ & $\begin{array}{c}(2) \\
\text { Cubic Spline }\end{array}$ & $\begin{array}{c}(3) \\
\text { LLR-1BW }\end{array}$ & $\begin{array}{c}(4) \\
\text { LLR-0.5BW }\end{array}$ \\
\hline \multicolumn{5}{|c|}{ Dependent Variable: Cutoff score in Previous Year } \\
\hline Score>Cutoff (1 yes) & $\begin{array}{l}-1.057 \\
(1.490)\end{array}$ & $\begin{array}{c}0.236 \\
(1.871)\end{array}$ & $\begin{array}{l}-0.016 \\
(2.054)\end{array}$ & $\begin{array}{l}-0.527 \\
(3.013)\end{array}$ \\
\hline Mean Dep. Var. & 67.996 & 67.996 & 68.528 & 68.632 \\
\hline Observations & 5232 & 5232 & 2508 & 1332 \\
\hline Clusters & 2907 & 2907 & 1316 & 670 \\
\hline \multicolumn{5}{|c|}{ Dependent Variable: Mean 12th Grade Score (Spanish) } \\
\hline Score $>$ Cutoff (1 yes) & $\begin{array}{l}-0.031 \\
(0.033)\end{array}$ & $\begin{array}{l}-0.040 \\
(0.039)\end{array}$ & $\begin{array}{l}-0.075 \\
(0.049)\end{array}$ & $\begin{array}{c}-0.134^{* *} \\
(0.064)\end{array}$ \\
\hline Mean Dep. Var. & 0.388 & 0.388 & 0.379 & 0.373 \\
\hline Observations & 5232 & 5232 & 2289 & 1216 \\
\hline Clusters & 2907 & 2907 & 1187 & 621 \\
\hline \multicolumn{5}{|c|}{ Dependent Variable: Mean 12th Grade Score (Math) } \\
\hline Score >Cutoff (1 yes) & $\begin{array}{l}-0.043 \\
(0.043)\end{array}$ & $\begin{array}{l}-0.042 \\
(0.051)\end{array}$ & $\begin{array}{l}-0.066 \\
(0.055)\end{array}$ & $\begin{array}{l}-0.128^{*} \\
(0.075)\end{array}$ \\
\hline Mean Dep. Var. & 0.437 & 0.437 & 0.432 & 0.420 \\
\hline Observations & 5232 & 5232 & 3098 & 1652 \\
\hline Clusters & 2907 & 2907 & 1638 & 851 \\
\hline \multicolumn{5}{|c|}{ Dependent Variable: June Pass Rate } \\
\hline Score $>$ Cutoff (1 yes) & $\begin{array}{l}0.017^{*} \\
(0.009)\end{array}$ & $\begin{array}{c}0.010 \\
(0.011)\end{array}$ & $\begin{array}{c}0.011 \\
(0.013)\end{array}$ & $\begin{array}{c}0.003 \\
(0.018)\end{array}$ \\
\hline Mean Dep. Var. & 0.660 & 0.660 & 0.659 & 0.663 \\
\hline Observations & 5232 & 5232 & 2445 & 1305 \\
\hline Clusters & 2907 & 2907 & 1281 & 658 \\
\hline
\end{tabular}

Note: ${ }^{*}$ significant at $10 \% ; * *$ significant at $5 \%$. OLS estimates for a polynomial specification in columns 1 and 2. Local Linear Regression estimates using the triangular Kernel in columns 3 and 4. The bandwidth is chosen according to the optimal criterion in Imbens and Kalyanaraman [2012]. Standard errors clustered by values of the eligibility score in parenthesis. Application-year dummies are included in all specifications.

effect of the transfer on the probability of being assigned to the first option through their underlying effects on preferences over schools/tracks (see Table 3) ${ }^{22}$ The GPA is strongly

\footnotetext{
${ }^{22}$ The increased probability of assignment to the first option might not be necessarily driven by a higher
} 
Table 6: The Effects of Cash Transfers on Parental Occupation Choices

\begin{tabular}{|c|c|c|c|c|}
\hline & $\begin{array}{c}\text { (1) } \\
\text { Quadratic Spline }\end{array}$ & $\begin{array}{c}(2) \\
\text { Cubic Spline }\end{array}$ & $\begin{array}{c}(3) \\
\text { LLR-1BW }\end{array}$ & $\begin{array}{c}(4) \\
\text { LLR-0.5BW }\end{array}$ \\
\hline \multicolumn{5}{|c|}{ Dependent Variable: Father is Self-Employed (1 yes) } \\
\hline Score $>$ Cutoff (1 yes) & $\begin{array}{c}0.014 \\
(0.034)\end{array}$ & $\begin{array}{c}0.038 \\
(0.041)\end{array}$ & $\begin{array}{c}0.018 \\
(0.040)\end{array}$ & $\begin{array}{c}0.071 \\
(0.056)\end{array}$ \\
\hline Mean Dep. Var. & 0.324 & 0.324 & 0.328 & 0.329 \\
\hline Observations & 5232 & 5232 & 3213 & 1746 \\
\hline Clusters & 2907 & 2907 & 1711 & 901 \\
\hline \multicolumn{5}{|c|}{ Dependent Variable: Mother is Self-Employed (1 yes) } \\
\hline Score $>$ Cutoff (1 yes) & $\begin{array}{l}-0.009 \\
(0.027)\end{array}$ & $\begin{array}{l}-0.027 \\
(0.034)\end{array}$ & $\begin{array}{l}-0.070^{*} \\
(0.039)\end{array}$ & $\begin{array}{l}-0.063 \\
(0.055)\end{array}$ \\
\hline Mean Dep. Var. & 0.158 & 0.158 & 0.165 & 0.165 \\
\hline Observations & 5232 & 5232 & 2146 & 1113 \\
\hline Clusters & 2907 & 2907 & 1108 & 571 \\
\hline
\end{tabular}

Note: * significant at $10 \%$. OLS estimates for a polynomial specification in columns 1 and 2 . Local Linear Regression estimates using the triangular Kernel in columns 3 and 4 . The bandwidth is chosen according to the optimal criterion in Imbens and Kalyanaraman [2012]. Standard errors clustered by values of the eligibility score in parenthesis. Application-year dummies are included in all specifications.

correlated with the exam score that determines the assignment, hence it is unlikely to observe large differences in assignment for those within a relatively small GPA interval. Consistently, we find that the size of the LATE is basically the same for Low and High GPA students, although both coefficients are not statistically different from zero (column 2). Using the same definition of High and Low distance as in Table 3, we indeed find that the LATE for the former is almost double in size than the LATE for the latter (column 3), although we cannot reject the null hypothesis at conventional levels that the two coefficients are the same.

probability of opting for the vocational track. Without modifying the preferred track choice, more liquidity constrained students may, in principle, have used the Oportunidades transfer to access more selective (and potentially more expensive) options. However, the evidence reported above is not consistent with any change induced by the program in the selectivity of the first option (see Table 5), and/or in the applicants' scores in the COMIPEMS exams (see Table B.2). Since these two are the only possible margins along which the program might have altered assignment outcomes in this setting, we are more inclined to interpret the observed changes in assignment as the result of a preference shift between, rather than within, tracks. 
Table 7: The Effect of Cash Transfers on the Probability of Assignment to the First Choice

\begin{tabular}{lccc}
\hline \hline & $(1)$ & $(2)$ & $(3)$ \\
\hline Takeup & $0.078^{*}$ & & \\
& $(0.047)$ & & \\
Takeup $\times$ Low GPA & \multicolumn{2}{c}{0.073} & \\
& & $(0.057)$ & \\
Takeup $\times$ High GPA & & 0.077 & \\
& & $(0.049)$ & \\
Takeup $\times$ Low Distance & & & 0.054 \\
& & & $(0.052)$ \\
Takeup $\times$ High Distance & & & $0.106^{* *}$ \\
& & 0.934 & 0.145 \\
\hline P value: Takeup $\times$ _low=Takeup $\times$ _high & 0.301 & 0.301 & 0.301 \\
Mean Dep. Var. & 5232 & 5232 & 5232 \\
Observations & 2907 & 2907 & 2907 \\
Clusters & & \\
\hline \hline
\end{tabular}

Note: $*$ significant at $10 \%$; ** significant at $5 \%$; *** significant at $1 \% .2$ SLS estimates (quadratic spline specification for the poverty score). Standard errors clustered by values of the poverty score in parenthesis. The score in the COMIPEMS exam (in deciles), and application-year dummies are included in all specifications.

\section{$5.2 \quad$ High School Outcomes}

We finally test whether or not the Oportunidades transfer led to an improvement in ontime high school completion, as proxied by the probability of taking the ENLACE 12th grade standardized exam three years after entry in high school. ${ }^{23}$ We contrast the results

\footnotetext{
${ }^{23}$ The 12th grade test is given to students who are on track to graduate at the end of the academic year, and previous work [Dustan et al., 2017] has found that it is a good proxy for the probability of completing high school on time. There are three main reasons why we focus on a proxy of on-time graduation when assessing the medium-term impact of the cash transfer. First, as already discussed above, in Mexico the share of students who complete high school on time is extremely low, and even lower among those in the vocational track. This might be the result of a mismatch between students and school characteristics, partly driven by the liquidity constraints that prevent students from choosing the school type that better fits their talents and aspirations. Second, by looking at on-time completion we can clearly disentangle the effect of the Oportunidades transfer induced by the change in preferences over high school tracks from the one induced by the conditionality of the high school component of the transfer (see Section 2.2). Since the scholarship is suspended after four years, the program conditionality does not provide incentives to complete high school in the statutory three years. On the contrary, the change in high school preferences associated with the relaxation of the liquidity constraints should be associated with a higher probability of completing high school on time, partly as a result of a better match. Finally, the take-up of the ENLACE 12th grade exam is
} 
for those who took the ENLACE exam being registered in a vocational school (column 1 in Table 8) with those who took the test either being registered in a general or a technical school (column 3 in Table 8). We find that receiving cash transfers led to an increase in the probability of completing high school on time for students in a professional option, by 2.7 percentage points. Although the coefficient is not statistically significant, the size of the effect is not negligible since it corresponds to 10 percent of the variable's standard deviation. However, receiving Oportunidades has a negative and marginally significant effect on the probability of completing high school in a general or a technical school. The negative coefficient in column 3 may possibly capture the interaction between the disincentives to graduate on time generated by the conditionality attached to the high school component of the Oportunidades transfer, and the very strict promotion rules of the high school system in Mexico. ${ }^{24}$ When we compare the LATE effects in columns 1 and 3, we can reject the null hypothesis that the two coefficients are not statistically different. We interpret this as evidence that for students attending a vocational school, the positive effect of Oportunidades on school performance generated through a change in school track preferences more than compensate the negative effect due to the program conditionality.

Consistently with the evidence discussed in sections 4.3 and 5.1, we find that the LATE on on-time high school completion is statistically larger for those who live further away from vocational schools (column 2 in Table 8). In order to rule out the possibility that the heterogeneity in distance is driven by confounding factors - e.g, Oportunidades might have differentially increased the returns to education in more remote areas, we test whether the LATE on on-time graduation for tracks other than vocational varies with distance and find no evidence to support this hypothesis (column 4 in Table 8).

the only high school outcome for which centralized administrative information is available. By matching the COMIPEMS takers in the municipality of Ecatepec with the nationwide universe of ENLACE exam takers, we are able to follow students irrespective of whether or not they have remained in the high school they had been originally assigned to.

${ }^{24}$ Students must pass five out of eight disciplinary subject areas and practical modules, otherwise they have to repeat the semester. Students who fail three or fewer subject areas can enroll in the next semester but they have to attend and pass intensive courses (the so called regularizacion) during a fixed time window. Partly as a result of the strict promotion rules, there are very high grade repetition and subject repetition rates, 15.3 percent and 31.3 percent respectively in 2013. Previous work has documented the perverse effect of Oportunidades on school performance in lower secondary [Dubois et al., 2012]. 
Table 8: The Effect of Cash Transfers on High School On-Time Completion

\begin{tabular}{lcccc}
\hline \hline & \multicolumn{2}{c}{ Vocational on Time } & \multicolumn{2}{c}{ Any Other Track on Time } \\
& $(1)$ & $(2)$ & $(3)$ & $(4)$ \\
\hline Takeup & 0.027 & & $-0.092^{*}$ & \\
& $(0.028)$ & & $(0.049)$ & \\
Takeup $\times$ Low Distance & & 0.006 & & $-0.094^{*}$ \\
& & $(0.030)$ & & $(0.053)$ \\
Takeup $\times$ High Distance & & $0.051^{*}$ & & -0.078 \\
& & $(0.030)$ & & $(0.053)$ \\
\hline P value: Takeup $\times$ low $=$ Takeup $\times$ high & & 0.048 & & 0.684 \\
Mean Dep. Var. & 0.073 & 0.073 & 0.326 & 0.326 \\
Observations & 5059 & 5059 & 5059 & 5059 \\
Clusters & 2856 & 2856 & 2856 & 2856 \\
\hline \hline
\end{tabular}

Note: * significant at $10 \%$; ** significant at $5 \%$; *** significant at $1 \%$. 2SLS estimates (quadratic spline specification for the poverty score). Standard errors clustered by values of the poverty score in parenthesis. The score in the COMIPEMS exam (in deciles), and application-year dummies are included in all specifications.

\section{Conclusions}

In spite of substantial differences in labor market returns by fields of study, there is little systematic evidence available on the factors underlying students' (and parents') demand for different curriculums (or tracks) in secondary education. Financial frictions and/or low income levels can induce students from disadvantaged backgrounds to opt for schooling options that do not correspond with either their skills or their career expectations. In this paper, we explore the extent to which differences in cost and benefit across high school tracks affect school choice decisions in the context of a high-stake assignment mechanism in the metropolitan area of Mexico City. Quasi-experimental evidence that stems from the discontinuity in the assignment of the Oportunidades cash transfer program documents that an income shock increases the probability of choosing the vocational track for the subpopulation of students in the neighborhood of the program eligibility cutoff by 6-7 percentage points. Although this is, by construction, a local effect that is difficult to extrapolate to other segments of the student population, it draws on a policy-relevant sample of low-income students in an urban setting within a large developing country.

As predicted by a standard school choice model with either credit constraints or a positive income elasticity of demand for schooling, this effect is more pronounced amongst students 
who are more likely to reap higher returns from a vocational education (i.e. lower GPA in lower secondary) and amongst those who are likely to face higher transportation costs in accessing the associated school facilities. We have also shown that these short-run responses to the cash transfer can translate into better academic trajectories in high school. These findings provide further empirical support for demand-side subsidies, which partly cover attendance and/or transportation costs (e.g. school vouchers) in order to increase enrollment rates and schooling outcomes at the secondary level. The extent to which these policy levers are able to improve transitions into the labor market and ultimately increase earnings is still an open question. ${ }^{25}$

\footnotetext{
${ }^{25}$ See Bettinger et al. [2017] and Duflo et al. [2017] for very recent evidence in Ghana and Colombia, respectively.
} 


\section{References}

Altonji, J., Arcidiacono, P. and Maurel, A. [2016], Chapter 7 - the analysis of field choice in college and graduate school: Determinants and wage effects, Vol. 5 of Handbook of the Economics of Education, Elsevier, pp. 305 - 396.

Altonji, J. G. [1995], 'The Effects of High School Curriculum on Education and Labor Market Outcomes', Journal of Human Resources 30(3), 409-438.

Altonji, J. G., Blom, E. and Meghir, C. [2012], 'Heterogeneity in Human Capital Investments: High School Curriculum, College Major, and Careers', Annual Review of Economics 4(1), 185-223.

Angelucci, M. [2015], 'Migration and Financial Constraints: Evidence from Mexico', The Review of Economics and Statistics 97(1), 224-228.

Angelucci, M. and Attanasio, O. [2009], 'Oportunidades: Program Effect on Consumption, Low Participation, and Methodological Issues', Economic Development and Cultural Change 57(3), 479-506.

Angelucci, M. and Attanasio, O. [2013], 'The Demand for Food of Poor Urban Mexican Households: Understanding Policy Impacts Using Structural Models', American Economic Journal: Economic Policy 5(1), 146-78.

Angrist, J., Bettinger, E., Bloom, E., King, E. and Kremer, M. [2002], 'Vouchers for Private Schooling in Colombia: Evidence from a Randomized Natural Experiment', American Economic Review 92(5), 1535-1558.

Angrist, J., Bettinger, E. and Kremer, M. [2006], 'Long-Term Educational Consequences of Secondary School Vouchers: Evidence from Administrative Records in Colombia', American Economic Review 96(3), 847-862.

Attanasio, O., Guarín, A., Medina, C. and Meghir, C. [2015], Long Term Impacts of Vouchers for Vocational Training: Experimental Evidence for Colombia, NBER Working Papers 21390, National Bureau of Economic Research, Inc.

Attanasio, O., Kugler, A. and Meghir, C. [2011], 'Subsidizing Vocational Training for Disadvantaged Youth in Colombia: Evidence from a Randomized Trial', American Economic Journal: Applied Economics 3(3), 188-220.

Banerjee, A., Karlan, D. and Zinman, J. [2015], 'Six Randomized Evaluations of Microcredit: Introduction and Further Steps', American Economic Journal: Applied Economics 7(1), 121.

Banerjee, A. V. and Newman, A. F. [1993], 'Occupational Choice and the Process of Development', Journal of Political Economy 101(2), 274-98.

Bettinger, E., Kremer, M., Kluger, M., Medina, C., Posso, C. and Saveedra, J. E. [2017], Can Educational Voucher Programs Pay for Themselves?, mimeo.

Bianchi, M. and Bobba, M. [2013], 'Liquidity, Risk, and Occupational Choices', Review of Economic Studies 80(2), 491-511.

Blattman, C., Fiala, N. and Martinez, S. [2014], 'Generating Skilled Self-Employment in Developing Countries: Experimental Evidence from Uganda', The Quarterly Journal of Economics 129(2), 697-752. 
Bobba, M. and Frisancho, V. [2016], Learning about Oneself: The Effects of Performance Feedback on School Choice, IZA Discussion Papers 10360, Institute for the Study of Labor (IZA).

Buser, T., Niederle, M. and Oosterbeek, H. [2014], 'Gender, Competitiveness, and Career Choices', The Quarterly Journal of Economics 129(3), 1409-1447.

Camacho, A. and Conover, E. [2011], 'Manipulation of Social Program Eligibility', American Economic Journal: Economic Policy 3(2), 41-65.

Canay, I. A. and Kamat, V. [2015], Approximate permutation tests and induced order statistics in the regression discontinuity design, CeMMAP working papers CWP27/15, Centre for Microdata Methods and Practice, Institute for Fiscal Studies.

Card, D., Ibarraran, P., Regalia, F., Rosas-Shady, D. and Soares, Y. [2011], 'The Labor Market Impacts of Youth Training in the Dominican Republic', Journal of Labor Economics $\mathbf{2 9}(2), 267-300$.

Deming, D. J., Hastings, J. S., Kane, T. J. and Staiger, D. O. [2014], 'School Choice, School Quality, and Postsecondary Attainment', American Economic Review 104(3), 991-1013.

Di Gropello, E. [2006], Meeting the Challenges of Secondary Education in Latin America and East Asia : Improving Efficiency and Resource Mobilization, number 7173 in 'World Bank Publications', The World Bank.

Dubois, P., de Janvry, A. and Sadoulet, E. [2012], 'Effects on School Enrollment and Performance of a Conditional Cash Transfer Program in Mexico', Journal of Labor Economics 30(3), $555-589$.

Duflo, E., Dupas, P. and Kremer, M. [2015], 'Education, HIV, and Early Fertility: Experimental Evidence from Kenya', American Economic Review 105(9), 2757-2797.

Duflo, E., Dupas, P. and Kremer, M. [2017], The Impact of Free Secondary Education: Experimental Evidence from Ghana, mimeo.

Dustan, A., de Janvry, A. and Sadoulet, E. [2017], 'Flourish or Fail? The Risky Reward of Elite High School Admission in Mexico City', Journal of Human Resources .

Dustmann, C., Puhani, P. A. and Schönberg, U. [2014], The Long-Term Effects of Early Track Choice, IZA Discussion Papers 7897, Institute for the Study of Labor (IZA).

Ferreyra, M., Avitabile, C., Botero Alvarez, J., Haimovich, F. and Urzua, S. [2017], At a Crossroads Higher Education in Latin America and the Caribbean, World Bank Group, Washington, DC.

Gale, D. and Shapley, L. S. [1962], 'College Admissions and the Stability of Marriage', The American Mathematical Monthly 69(1), 9-15.

Ghatak, M., Morelli, M. and Sjöström, T. [2001], 'Occupational Choice and Dynamic Incentives', Review of Economic Studies 68(4), 781-810.

Giustinelli, P. [2016], 'Group Decision Making With Uncertain Outcomes: Unpacking the Role of Child-Parent Choice of the High School Track', International Economic Review $\mathbf{5 7}(2), 573-602$. 
Gonzalez-Flores, M., Heracleous, M. and Winters, P. [2012], 'Leaving the Safety Net: An Analysis of Dropouts in an Urban Conditional Cash Transfer Program', World Development 40(12), 2505-2521.

Hahn, J., Todd, P. and Van der Klaauw, W. [2001], 'Identification and Estimation of Treatment Effects with a Regression-Discontinuity Design', Econometrica 69(1), 201-09.

Imbens, G. and Kalyanaraman, K. [2012], 'Optimal Bandwidth Choice for the Regression Discontinuity Estimator', Review of Economic Studies 79(3), 933-959.

Lee, D. S. [2008], 'Randomized experiments from non-random selection in U.S. House elections', Journal of Econometrics 142(2), 675-697.

Lee, D. S. and Card, D. [2008], 'Regression discontinuity inference with specification error', Journal of Econometrics 142(2), 655-674.

Lee, D. S. and Lemieux, T. [2010], 'Regression Discontinuity Designs in Economics', Journal of Economic Literature 48(2), 281-355.

Lochner, L. and Monge-Naranjo, A. [2012], 'Credit Constraints in Education', Annual Review of Economics 4, 225-256.

Lucas, A. M. and Mbiti, I. M. [2012], 'Access, Sorting, and Achievement: The Short-Run Effects of Free Primary Education in Kenya', American Economic Journal: Applied Economics 4(4), 226-253.

Martinelli, C. and Parker, S. W. [2009], 'Deception and misreporting in a social program', Journal of the European Economic Association 7(4), 886-908.

McCrary, J. [2008], 'Manipulation of the running variable in the regression discontinuity design: A density test', Journal of Econometrics 142(2), 698-714.

Meer, J. [2007], 'Evidence on the returns to secondary vocational education', Economics of Education Review 26(5), 559-573.

Schultz, T. [2004], 'School subsidies for the poor: Evaluating the mexican progresa poverty program', Journal of Development Economics 74(1), 199-250.

Skoufias, E., Davis, B. and de la Vega, S. [2001], 'Targeting the Poor in Mexico: An Evaluation of the Selection of Households into PROGRESA', World Development 29(10), 17691784.

Tarozzi, A., Desai, J. and Johnson, K. [2015], 'The Impacts of Microcredit: Evidence from Ethiopia', American Economic Journal: Applied Economics 7(1), 54-89. 


\section{Appendix}

\section{A Descriptive Evidence}

Figure A.1: Empirical Densities of the School Cutoff Scores by High School Track

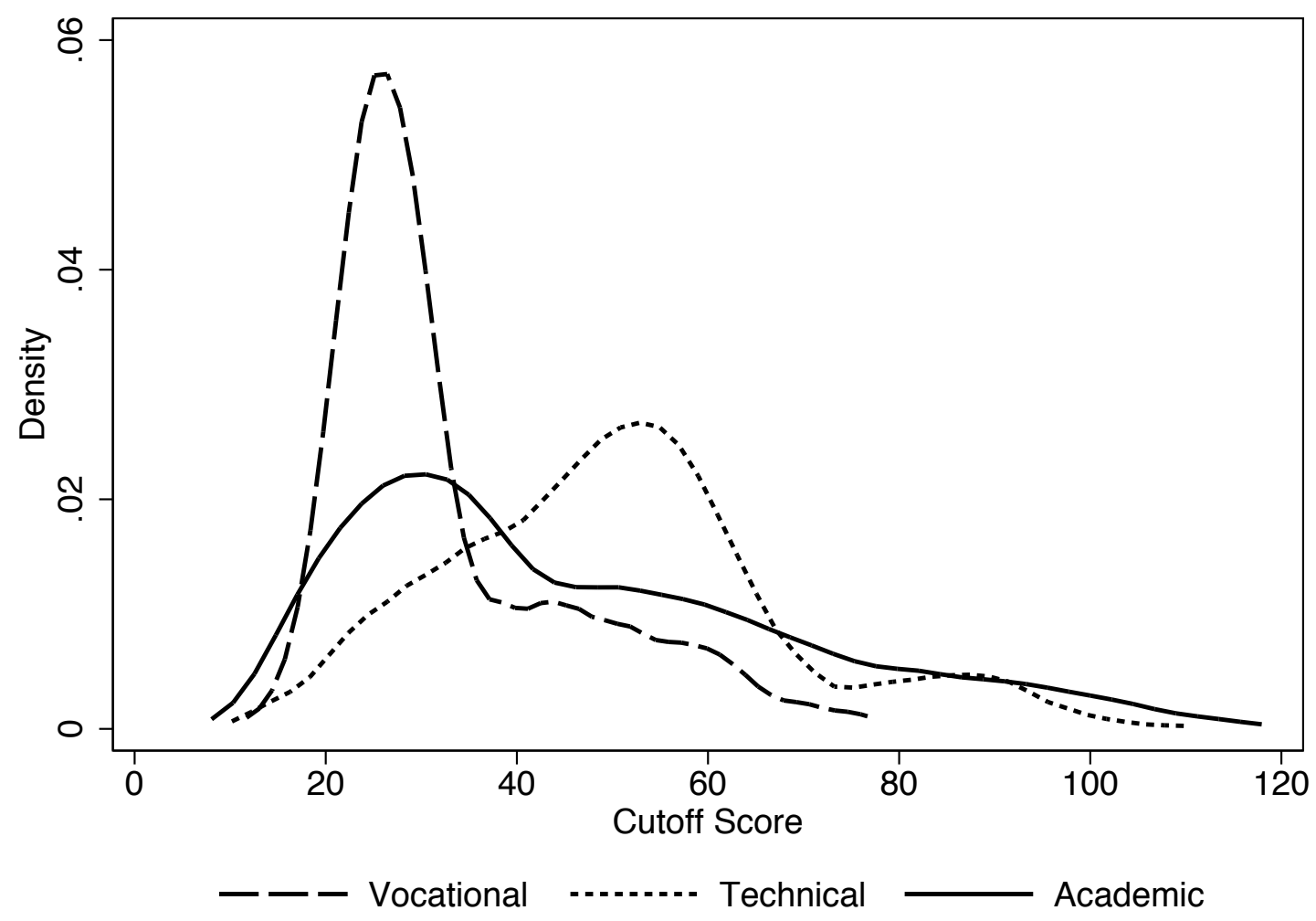

Notes: Cutoff scores are defined as lowest score in the admission exam for each school participating in the COMIPEMS system. Source: COMIPEMS administrative data (2010). 
Table A.1: Comparison of Mean Characteristics of the Municipality of Ecatepec with Mexico City and Rest of Mexico

\begin{tabular}{|c|c|c|c|c|}
\hline & $\begin{array}{c}(1) \\
\text { Ecatepec }\end{array}$ & $\begin{array}{c}(2) \\
\text { Other Mun. in } \\
\text { State of Mexico }\end{array}$ & $\begin{array}{c}(3) \\
\text { Federal } \\
\text { District }\end{array}$ & $\begin{array}{c}(4) \\
\text { Rest of } \\
\text { Mexico }\end{array}$ \\
\hline \multicolumn{5}{|l|}{ Panel A: Firms' characteristics } \\
\hline Firm Size & 3.50 & 4.12 & 7.83 & 4.71 \\
\hline Gross VA per worker (MX $\$$ thous.) & 570.5 & 720.5 & 2517.4 & 756.5 \\
\hline K per firm (MX\$ thous.) & 408.2 & 698.0 & 1533.1 & 883.1 \\
\hline \multicolumn{5}{|l|}{$\underline{\text { Panel B: Labor market }}$} \\
\hline Unemployment rate & 0.045 & 0.046 & 0.063 & 0.040 \\
\hline Labor earnings (hourly MX\$) & 25.77 & 27.61 & 34.61 & 30.97 \\
\hline \multicolumn{5}{|l|}{ Panel C: Socio-demographics } \\
\hline School enrollment rate (age 6 -14) & 0.90 & 0.89 & 0.91 & 0.82 \\
\hline Poverty index & 2.67 & 2.87 & 1.41 & 2.05 \\
\hline \multicolumn{5}{|l|}{ Panel D: COMIPEMS applicants } \\
\hline Family income (categorical) & 4.67 & 4.71 & 5.47 & \\
\hline Father educ. (categorical) & 5.49 & 5.40 & 6.14 & \\
\hline Mother educ. (categorical) & 5.00 & 4.94 & 5.63 & \\
\hline Indigenous & 0.045 & 0.046 & 0.029 & \\
\hline Probability of assignment & 0.82 & 0.81 & 0.77 & \\
\hline First option in the same Municipality & 0.45 & 0.35 & 0.40 & \\
\hline First option is over-subscribed & 0.55 & 0.51 & 0.70 & \\
\hline First option is vocational & 0.07 & 0.08 & 0.07 & \\
\hline First option is general & 0.53 & 0.63 & 0.72 & \\
\hline First option is technical & 0.40 & 0.29 & 0.21 & \\
\hline
\end{tabular}

Source: Mexican economic census, 2008 (Panel A), labor market survey, 2008 (Panel B), population census, 2000 (Panel C), and COMIPEMS administrative data, 2008 (Panel D). 
Figure A.2: The Geographic Distribution of COMIPEMS Options
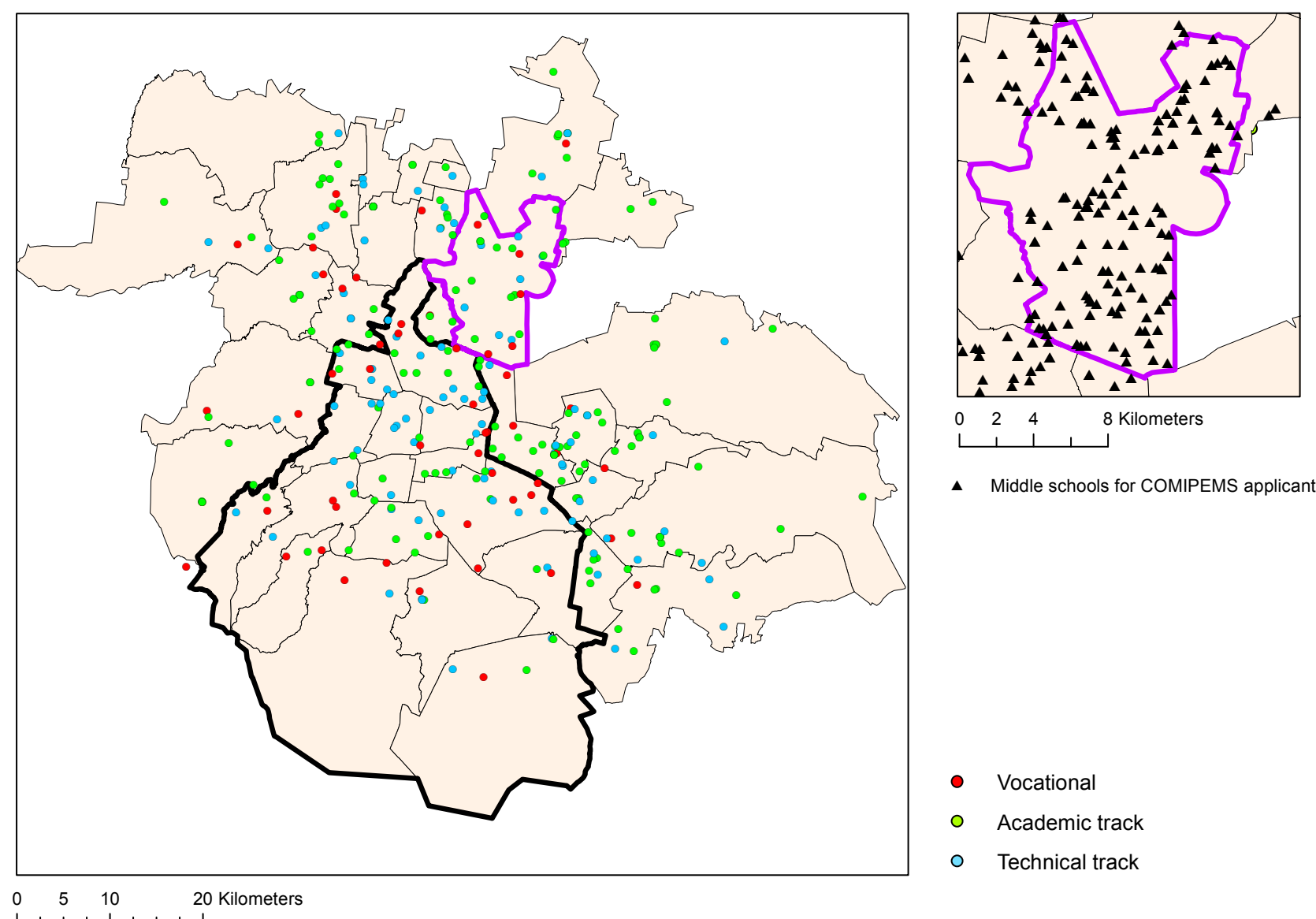

- Middle schools for COMIPEMS applicants

Vocational

- Academic track

○ Technical track

Notes: This map reports the geographic locations of the schooling options that participate to the COMIPEMS assignment system during the period 2005-2010. The thick black line denotes the geographic border between the Federal District and the State of Mexico. The thin grey lines indicate the borders of the different municipalities that participate in the COMIPEMS system. The quadrant in the up-right corner displays a close-up view of the Municipality of Ecatepec in which the markers reflect the locations of the middle-schools of origin for the applicants in our sample. 
Figure A.3: Type of Preferred Technical Program (1st Option) by Track

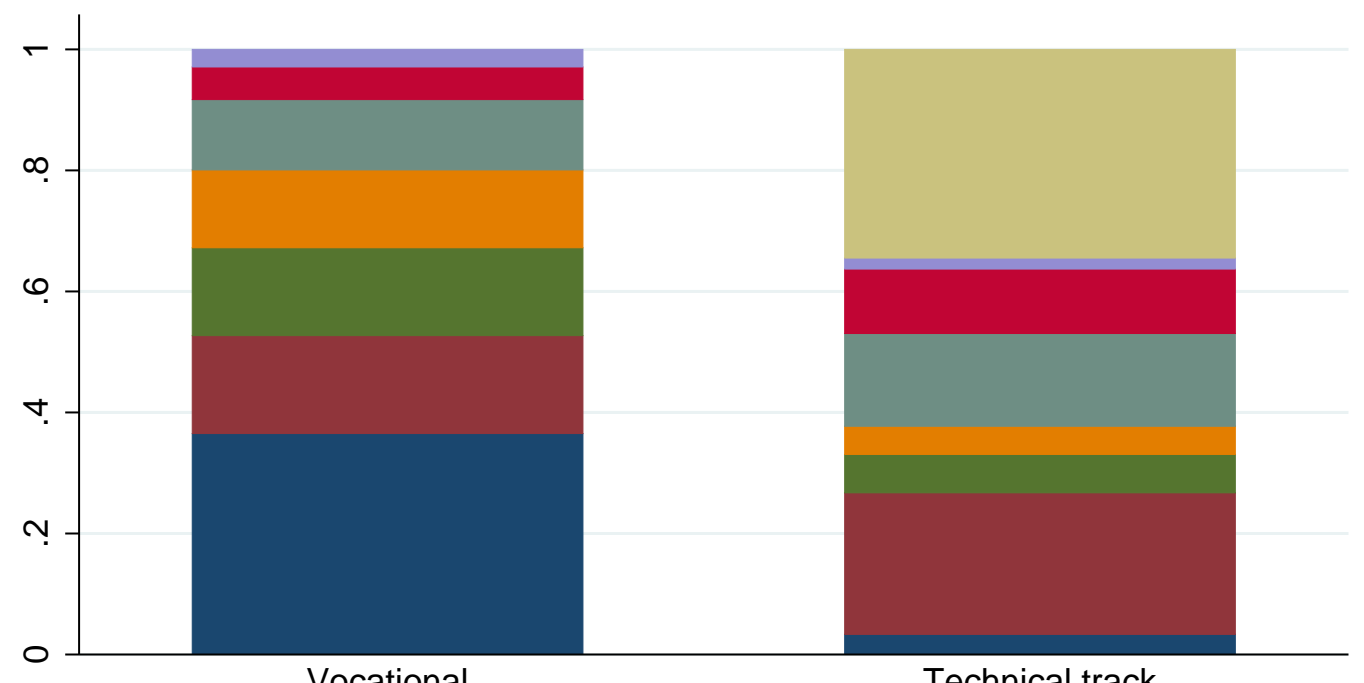

Vocational

Technical track

\begin{tabular}{|l|l|}
\hline Maintenance & Information technology \\
\hline Electronics & Production process \\
\hline Accounting and Administration & Health/Social \\
\hline Tourism/Cosmetology & Mixed specializations \\
\hline
\end{tabular}

NotE: This figure reports the within track composition among the applicants' first choices for some aggregated categories of curricular sub-specializations that allow for a direct comparison between the vocational and the technical tracks. 
Table A.2: Labor Market Returns to High School Tracks

\begin{tabular}{lccc}
\hline \hline Dependent Variable & \multicolumn{3}{c}{ Log Hourly Earnings } \\
Sample & All & Male & Female \\
& $(1)$ & $(2)$ & $(3)$ \\
\hline Highest Degree is Secondary & $-0.486^{* * *}$ & $-0.441^{* * *}$ & $-0.531^{* * *}$ \\
& $(0.025)$ & $(0.030)$ & $(0.031)$ \\
Highest Degree is Secondary $\times$ Technical & $0.074^{*}$ & 0.061 & $0.076^{*}$ \\
& $(0.040)$ & $(0.047)$ & $(0.044)$ \\
Highest Degree is Secondary $\times$ Vocational & $0.143^{* * *}$ & $0.155^{* * *}$ & $0.130^{* *}$ \\
& $(0.035)$ & $(0.053)$ & $(0.051)$ \\
Technical & $-0.059^{*}$ & -0.034 & $-0.080^{* *}$ \\
& $(0.034)$ & $(0.044)$ & $(0.034)$ \\
Vocational & & & \\
& $-0.103^{* * *}$ & $-0.127^{* * *}$ & $-0.072^{* *}$ \\
Male & $(0.032)$ & $(0.046)$ & $(0.033)$ \\
& $0.053^{* * *}$ & & \\
Urban & $(0.013)$ & & \\
& & & \\
\hline Number of Observations & $0.094^{* * *}$ & $0.124^{* * *}$ & 0.061 \\
Number of Clusters & $(0.024)$ & $(0.022)$ & $(0.038)$ \\
\hline \hline
\end{tabular}

Notes: * significant at $10 \%$; ** significant at $5 \%$; *** significant at $1 \%$. OLS estimates. Standard errors are clustered at the State level. Labor earnings are computed for employed individuals between 16 and 35 years old who have completed at least lower secondary education and went to a public high school in Mexico. Dummies for age and State of residence are included in all specifications but are not reported. Source: Mexico's labor market survey linked with retrospective survey on educational trajectories (ENOE-ENTELEMS, 2008). 
Figure A.4: Subjective Expectations about Monthly Earnings for High School graduates by Track

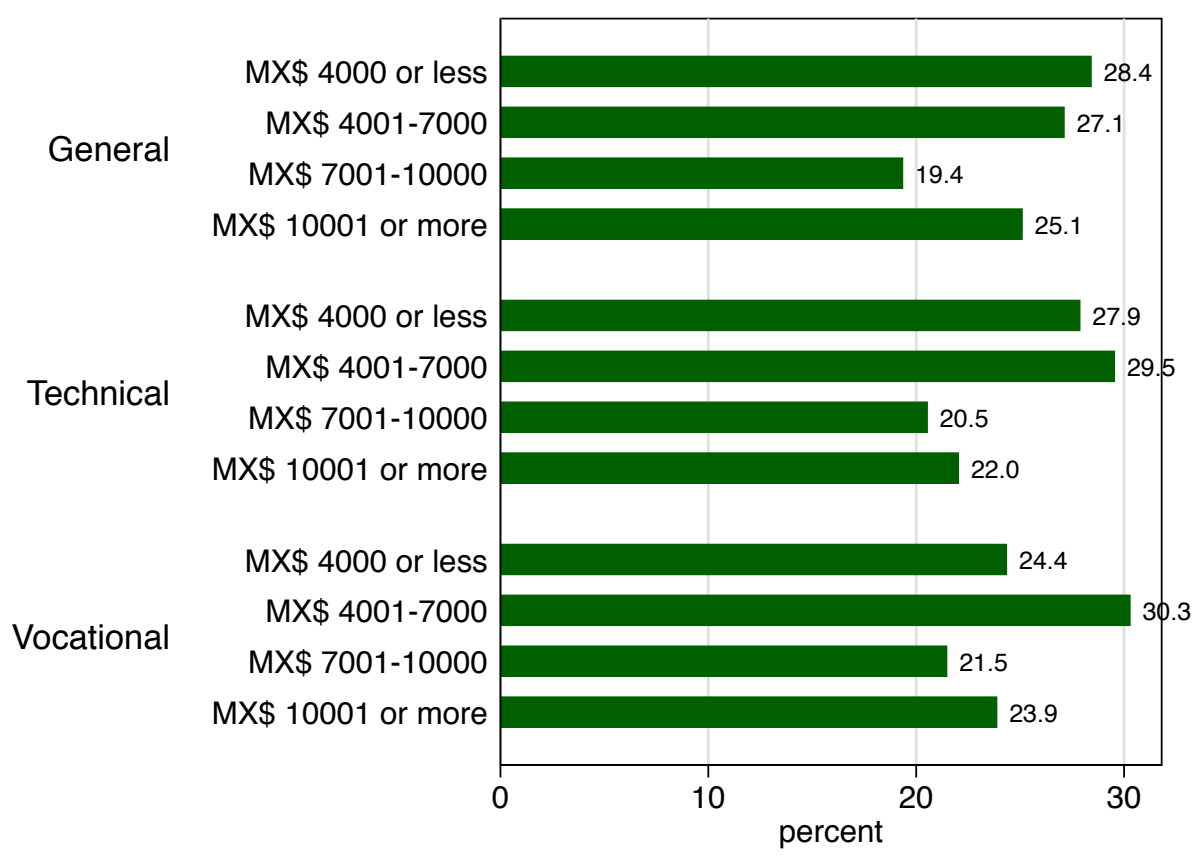

Notes: For each academic track, we report students' expected income distribution within 5 years from high school graduation, in case they decide not to continue their studies and obtain a university degree. Nationally-representative sample of students who take a standardized end of high school test (ENLACE, 2009). 


\section{B Validity of the RD Design: Further Evidence}

Table B.1: Covariate Smoothness

\begin{tabular}{|c|c|c|c|c|}
\hline & $\begin{array}{c}\text { (1) } \\
\text { Quadratic Spline }\end{array}$ & $\begin{array}{c}(2) \\
\text { Cubic Spline }\end{array}$ & $\begin{array}{c}(3) \\
\text { LLR-1BW }\end{array}$ & $\begin{array}{c}(4) \\
\text { LLR-0.5BW }\end{array}$ \\
\hline \multicolumn{5}{|c|}{ Dependent Variable: Applicant's Age } \\
\hline Score >Cutoff (1 yes) & $\begin{array}{l}-0.005 \\
(0.064)\end{array}$ & $\begin{array}{l}-0.019 \\
(0.078)\end{array}$ & $\begin{array}{l}-0.013 \\
(0.075)\end{array}$ & $\begin{array}{c}0.031 \\
(0.106)\end{array}$ \\
\hline Mean Dep. Var. & 15.440 & 15.440 & 15.437 & 15.449 \\
\hline Number of Obs & 5232 & 5232 & 3058 & 1621 \\
\hline Number of Clusters & 2907 & 2907 & 1618 & 833 \\
\hline \multicolumn{5}{|c|}{ Dependent Variable: Applicant is Indigenous (1 yes) } \\
\hline Score $>$ Cutoff (1 yes) & $\begin{array}{l}-0.010 \\
(0.023)\end{array}$ & $\begin{array}{l}-0.012 \\
(0.028)\end{array}$ & $\begin{array}{l}-0.015 \\
(0.025)\end{array}$ & $\begin{array}{l}-0.007 \\
(0.035)\end{array}$ \\
\hline Mean Dep. Var. & 0.095 & 0.095 & 0.084 & 0.088 \\
\hline Number of Obs & 5232 & 5232 & 3162 & 1696 \\
\hline Number of Clusters & 2907 & 2907 & 1682 & 876 \\
\hline \multicolumn{5}{|c|}{ Dependent Variable: Number of HH members } \\
\hline Score $>$ Cutoff (1 yes) & $\begin{array}{l}-0.043 \\
(0.108)\end{array}$ & $\begin{array}{c}0.066 \\
(0.132)\end{array}$ & $\begin{array}{l}-0.002 \\
(0.113)\end{array}$ & $\begin{array}{c}0.113 \\
(0.154)\end{array}$ \\
\hline Mean Dep. Var. & 5.101 & 5.101 & 4.914 & 4.914 \\
\hline Number of Obs & 5232 & 5232 & 3401 & 1858 \\
\hline Number of Clusters & 2907 & 2907 & 1819 & 955 \\
\hline \multicolumn{5}{|c|}{ Dependent Variable: Number of Disabled HH members } \\
\hline Score $>$ Cutoff (1 yes) & $\begin{array}{c}0.031 \\
(0.028)\end{array}$ & $\begin{array}{c}0.034 \\
(0.035)\end{array}$ & $\begin{array}{c}0.037 \\
(0.035)\end{array}$ & $\begin{array}{c}0.009 \\
(0.046)\end{array}$ \\
\hline Mean Dep. Var. & 0.105 & 0.105 & 0.099 & 0.101 \\
\hline Number of Obs & 5232 & 5232 & 2711 & 1428 \\
\hline Number of Clusters & 2907 & 2907 & 1427 & 723 \\
\hline \multicolumn{5}{|c|}{ Dependent Variable: Share of Children Enrolled in School } \\
\hline Score $>$ Cutoff (1 yes) & $\begin{array}{l}-0.013 \\
(0.016)\end{array}$ & $\begin{array}{l}-0.028 \\
(0.020)\end{array}$ & $\begin{array}{l}-0.010 \\
(0.021)\end{array}$ & $\begin{array}{l}-0.043 \\
(0.028)\end{array}$ \\
\hline Mean Dep. Var. & 0.900 & 0.900 & 0.897 & 0.907 \\
\hline Number of Obs & 5232 & 5232 & 2408 & 1285 \\
\hline Number of Clusters & 2907 & 2907 & 1257 & 647 \\
\hline \multicolumn{5}{|c|}{ Dependent Variable: Number of Children in Primary } \\
\hline Score $>$ Cutoff $\overline{(1 \text { yes })}$ & $\begin{array}{l}-0.029 \\
(0.074)\end{array}$ & $\begin{array}{l}-0.036 \\
(0.092)\end{array}$ & $\begin{array}{l}-0.050 \\
(0.072)\end{array}$ & $\begin{array}{l}-0.023 \\
(0.096)\end{array}$ \\
\hline Mean Dep. Var. & 1.570 & 1.570 & 1.474 & 1.449 \\
\hline
\end{tabular}

Continued on Next Page. 


\begin{tabular}{|c|c|c|c|c|}
\hline & $\begin{array}{c}\text { (1) } \\
\text { Quadratic Spline }\end{array}$ & $\begin{array}{c}(2) \\
\text { Cubic Spline }\end{array}$ & $\begin{array}{c}(3) \\
\text { LLR-1BW }\end{array}$ & $\begin{array}{c}(4) \\
\text { LLR-0.5BW }\end{array}$ \\
\hline Number of Obs & 5232 & 5232 & 4168 & 2367 \\
\hline Number of Clusters & 2907 & 2907 & 2230 & 1233 \\
\hline \multicolumn{5}{|c|}{ Dependent Variable: Number of Children in Secondary } \\
\hline Score $>$ Cutoff (1 yes) & $\begin{array}{c}-0.037 \\
(0.084)\end{array}$ & $\begin{array}{l}-0.025 \\
(0.104)\end{array}$ & $\begin{array}{c}0.006 \\
(0.100)\end{array}$ & $\begin{array}{c}0.107 \\
(0.148)\end{array}$ \\
\hline Mean Dep. Var. & 0.807 & 0.807 & 0.823 & 0.810 \\
\hline Number of Obs & 5232 & 5232 & 3126 & 1673 \\
\hline Number of Clusters & 2907 & 2907 & 1657 & 863 \\
\hline \multicolumn{5}{|c|}{ Dependent Variable: HH Head's Education Attainment (years) } \\
\hline Score $>$ Cutoff (1 yes) & $\begin{array}{l}-0.144 \\
(0.209)\end{array}$ & $\begin{array}{l}-0.141 \\
(0.257)\end{array}$ & $\begin{array}{l}-0.150 \\
(0.257)\end{array}$ & $\begin{array}{l}-0.528 \\
(0.349)\end{array}$ \\
\hline Mean Dep. Var. & 6.583 & 6.583 & 6.778 & 6.636 \\
\hline Number of Obs & 5232 & 5232 & 2711 & 1428 \\
\hline Number of Clusters & 2907 & 2907 & 1427 & 723 \\
\hline \multicolumn{5}{|c|}{ Dependent Variable: HH Spouse's Education Attainment (years) } \\
\hline Score $>$ Cutoff (1 yes) & $\begin{array}{c}0.081 \\
(0.200)\end{array}$ & $\begin{array}{c}0.125 \\
(0.245)\end{array}$ & $\begin{array}{c}0.240 \\
(0.258)\end{array}$ & $\begin{array}{c}0.266 \\
(0.369)\end{array}$ \\
\hline Mean Dep. Var. & 5.126 & 5.126 & 5.329 & 5.233 \\
\hline Number of Obs & 5232 & 5232 & 3010 & 1587 \\
\hline Number of Clusters & 2907 & 2907 & 1589 & 814 \\
\hline \multicolumn{5}{|c|}{ Dependent Variable: HH Head Working (1 yes) } \\
\hline Score $>$ Cutoff (1 yes) & $\begin{array}{l}-0.034 \\
(0.025)\end{array}$ & $\begin{array}{l}-0.019 \\
(0.033)\end{array}$ & $\begin{array}{l}-0.035 \\
(0.031)\end{array}$ & $\begin{array}{l}-0.011 \\
(0.045)\end{array}$ \\
\hline Mean Dep. Var. & 0.905 & 0.905 & 0.901 & 0.903 \\
\hline Number of Obs & 5232 & 5232 & 3434 & 1877 \\
\hline Number of Clusters & 2907 & 2907 & 1840 & 965 \\
\hline \multicolumn{5}{|c|}{ Dependent Variable: HH Spouse Working (1 yes) } \\
\hline Score $>$ Cutoff $(1 \overline{\text { yes }})$ & $\begin{array}{l}-0.002 \\
(0.028)\end{array}$ & $\begin{array}{c}-0.059^{*} \\
(0.036)\end{array}$ & $\begin{array}{l}-0.039 \\
(0.033)\end{array}$ & $\begin{array}{l}-0.047 \\
(0.046)\end{array}$ \\
\hline Mean Dep. Var. & 0.099 & 0.099 & 0.104 & 0.104 \\
\hline Number of Obs & 5232 & 5232 & 3010 & 1587 \\
\hline Number of Clusters & 2907 & 2907 & 1589 & 814 \\
\hline
\end{tabular}

Note: * significant at 10\%. OLS estimates for a polynomial specification in columns 1 and 2 . Local Linear Regression estimates using the triangular Kernel in columns 3 and 4 . The bandwidth is chosen for each dependent variable according to the optimal criterion in Imbens and Kalyanaraman [2012]. Standard errors clustered by values of the eligibility score in parenthesis. Application-year dummies are included in all specifications. 
Table B.2: Test for Compositional Changes

\begin{tabular}{|c|c|c|c|c|}
\hline & $\begin{array}{c}\text { (1) } \\
\text { Quadratic Spline }\end{array}$ & $\begin{array}{c}(2) \\
\text { Cubic Spline }\end{array}$ & $\begin{array}{c}(3) \\
\text { LLR-1BW }\end{array}$ & $\begin{array}{c}(4) \\
\text { LLR-0.5BW }\end{array}$ \\
\hline \multicolumn{5}{|c|}{ Dependent Variable: Individual in COMIPEMS registries (1 yes) } \\
\hline Score $>$ Cutoff (1 yes) & $\begin{array}{c}0.006 \\
(0.025)\end{array}$ & $\begin{array}{l}-0.029 \\
(0.032)\end{array}$ & $\begin{array}{c}0.008 \\
(0.026)\end{array}$ & $\begin{array}{l}-0.028 \\
(0.036)\end{array}$ \\
\hline Mean Dep. Var. & 0.421 & 0.421 & 0.446 & 0.449 \\
\hline Observations & 12428 & 12428 & 8549 & 4782 \\
\hline Clusters & 4924 & 4924 & 3301 & 1803 \\
\hline \multicolumn{5}{|c|}{ Dependent Variable: Score in the COMIPEMS Exam } \\
\hline Score $>$ Cutoff (1 yes) & $\begin{array}{l}-0.966 \\
(1.260)\end{array}$ & $\begin{array}{c}0.063 \\
(1.534)\end{array}$ & $\begin{array}{l}-0.136 \\
(1.433)\end{array}$ & $\begin{array}{c}0.186 \\
(1.963)\end{array}$ \\
\hline Mean Dep. Var. & 55.8 & 55.8 & 56.4 & 56.5 \\
\hline Observations & 5232 & 5232 & 3015 & 1587 \\
\hline Clusters & 2907 & 2907 & 1592 & 814 \\
\hline \multicolumn{5}{|c|}{ Dependent Variable: GPA in Lower Secondary } \\
\hline Score $>$ Cutoff (1 yes) & $\begin{array}{l}-0.009 \\
(0.058)\end{array}$ & $\begin{array}{c}0.048 \\
(0.069)\end{array}$ & $\begin{array}{c}0.041 \\
(0.084)\end{array}$ & $\begin{array}{l}-0.053 \\
(0.110)\end{array}$ \\
\hline Mean Dep. Var. & 7.35 & 7.35 & 7.32 & 7.24 \\
\hline Observations & 5232 & 5232 & 1861 & 955 \\
\hline Clusters & 2907 & 2907 & 957 & 487 \\
\hline \multicolumn{5}{|c|}{ Dependent Variable: Geodesic Distance $(\mathrm{Km})$ to the Closest Vocational School } \\
\hline Score $>$ Cutoff (1 yes) & $\begin{array}{c}0.026 \\
(0.132)\end{array}$ & $\begin{array}{c}0.011 \\
(0.162)\end{array}$ & $\begin{array}{c}0.088 \\
(0.179)\end{array}$ & $\begin{array}{c}0.322 \\
(0.249)\end{array}$ \\
\hline Mean Dep. Var. & 3.04 & 3.04 & 2.99 & 3.02 \\
\hline Observations & 5232 & 5232 & 2370 & 1273 \\
\hline Clusters & 2907 & 2907 & 1234 & 640 \\
\hline
\end{tabular}

NotE: OLS estimates for a polynomial specification in columns 1 and 2. Local Linear Regression estimates using the triangular Kernel in columns 3 and 4 . The bandwidth is chosen according to the optimal criterion in Imbens and Kalyanaraman [2012]. Standard errors clustered by values of the eligibility score are reported in parenthesis. Application-year dummies are included in all specifications. 


\section{RD Estimates: Alternative Specifications}

Table C.1: The Effects of Cash Transfers on Track Choices - Cubic Splines

\begin{tabular}{|c|c|c|c|}
\hline Estimator (parameter) & $\begin{array}{l}\text { Vocational } \\
\text { (1) }\end{array}$ & $\begin{array}{c}\text { General } \\
(2)\end{array}$ & $\begin{array}{c}\text { Technical } \\
\text { (3) }\end{array}$ \\
\hline$O L S(I T T)$ & & & \\
\hline Score $>$ Cutoff (1 yes) & $\begin{array}{l}0.046^{*} \\
(0.024)\end{array}$ & $\begin{array}{c}0.008 \\
(0.046)\end{array}$ & $\begin{array}{l}-0.054 \\
(0.045)\end{array}$ \\
\hline 2SLS (IV-LATE) & & & \\
\hline Takeup & $\begin{array}{l}0.071^{*} \\
(0.037)\end{array}$ & $\begin{array}{c}0.012 \\
(0.071)\end{array}$ & $\begin{array}{l}-0.083 \\
(0.070)\end{array}$ \\
\hline Mean Dependent Variable & 0.092 & 0.465 & 0.443 \\
\hline SD Dependent Variable & 0.289 & 0.499 & 0.497 \\
\hline Number of Observations & 5232 & 5232 & 5232 \\
\hline Number of Clusters & 2907 & 2907 & 2907 \\
\hline
\end{tabular}

Note: $*$ significant at $10 \%$; $* *$ significant at $5 \%$; *** significant at $1 \%$. Cubic spline specification for the eligibility score. Standard errors clustered by values of the eligibility score in parenthesis. The dependent variable Vocational/General/Technical takes the value 1 if a Vocational/General/Technical option is listed first in the applicant's portfolio. 
Table C.2: The Effects of Cash Transfers on Track Choices - Local Linear Regressions

\begin{tabular}{|c|c|c|c|}
\hline Estimator (parameter) & $\begin{array}{c}\text { Vocational } \\
\text { (1) }\end{array}$ & $\begin{array}{c}\text { General } \\
(2)\end{array}$ & $\begin{array}{c}\text { Technical } \\
(3)\end{array}$ \\
\hline Local Linear Regression (ITT) & \multirow[b]{2}{*}{$\begin{array}{c}0.046^{* *} \\
(0.020)\end{array}$} & \multirow[b]{2}{*}{$\begin{array}{c}0.015 \\
(0.043)\end{array}$} & \multirow[b]{2}{*}{$\begin{array}{l}-0.068 \\
(0.045)\end{array}$} \\
\hline Score $>$ Cutoff (1 yes) & & & \\
\hline Local Linear Regression (IV-LATE) & \multirow[b]{2}{*}{$\begin{array}{c}0.070 * * \\
(0.031)\end{array}$} & \multirow[b]{2}{*}{$\begin{array}{c}0.024 \\
(0.066)\end{array}$} & \multirow[b]{2}{*}{$\begin{array}{l}-0.106 \\
(0.071)\end{array}$} \\
\hline Takeup & & & \\
\hline Mean Dependent Variable & 0.090 & 0.473 & 0.444 \\
\hline SD Dependent Variable & 0.286 & 0.499 & 0.497 \\
\hline Number of Observations & 3908 & 3143 & 2792 \\
\hline Number of Clusters & 2093 & 1670 & 1468 \\
\hline
\end{tabular}

Note: ${ }^{*}$ significant at $10 \% ;{ }^{* *}$ significant at $5 \% ; * * *$ significant at $1 \%$.

Local Linear Regression estimates using the triangular Kernel. Standard errors clustered by values of the eligibility score in parenthesis. The bandwidth is chosen according to the optimal criterion in Imbens and Kalyanaraman [2012].

Table C.3: The Effects of Cash Transfers on Track Choices MLOGIT Marginal effects (ITT)

\begin{tabular}{|c|c|c|c|}
\hline & $\begin{array}{c}\text { Vocational } \\
\quad(1)\end{array}$ & $\begin{array}{c}\text { General } \\
(2)\end{array}$ & $\begin{array}{c}\text { Technical } \\
(3)\end{array}$ \\
\hline Quadratic Spline & \multirow[b]{2}{*}{$\begin{array}{c}0.047^{* *} \\
(0.023)\end{array}$} & \multirow[b]{2}{*}{$\begin{array}{c}0.010 \\
(0.037)\end{array}$} & \multirow[b]{2}{*}{$\begin{array}{l}-0.057 \\
(0.036)\end{array}$} \\
\hline Score $>$ Cutoff (1 yes) & & & \\
\hline Cubic Spline & \multirow[b]{2}{*}{$\begin{array}{l}0.052^{*} \\
(0.028)\end{array}$} & \multirow[b]{2}{*}{$\begin{array}{c}0.002 \\
(0.047)\end{array}$} & \multirow[b]{2}{*}{$\begin{array}{l}-0.054 \\
(0.045)\end{array}$} \\
\hline Score $>$ Cutoff (1 yes) & & & \\
\hline Log Pseudo-likelihood & \multicolumn{3}{|c|}{-4885.72} \\
\hline Number of Observations & \multicolumn{3}{|c|}{5232} \\
\hline Number of Clusters & \multicolumn{3}{|c|}{2907} \\
\hline
\end{tabular}

Note: $*$ significant at $10 \%$; ${ }^{* *}$ significant at $5 \%$; *** significant at $1 \%$. Maximum Likelihood estimates. Standard errors clustered by values of the poverty score are reported in parenthesis. The dependent variable takes discrete consecutive values for Vocational/General/Technical option as listed first in the applicant's portfolio. 
Table C.4: Heterogeneous LATE on Vocational Choice - Cubic Splines

\begin{tabular}{lcccc}
\hline \hline Sample & $(1)$ & $(2)$ & $(3)$ & $(4)$ \\
& All & All & Low GPA & High GPA \\
\hline Takeup $\times$ Low GPA & $0.125^{* * *}$ & & & \\
Takeup $\times$ High GPA & $(0.039)$ & & & \\
& 0.013 & & & \\
Takeup $\times$ Low Distance & $(0.037)$ & & & \\
& & 0.055 & 0.095 & 0.029 \\
Takeup $\times$ High Distance & & $(0.038)$ & $(0.063)$ & $(0.049)$ \\
& & & & \\
P value H0: treatX_low=treatX_high & 0.000 & $0.079^{* *}$ & $0.143^{* *}$ & 0.033 \\
Observations & 5232 & 5232 & 2443 & 2789 \\
Clusters & 2907 & 2907 & 1739 & 1916 \\
\hline \hline
\end{tabular}

Note: ${ }^{*}$ significant at $10 \%$; ${ }^{*}$ significant at $5 \%$; ** significant at $1 \%$. 2 SLS estimates (cubic spline specification for the eligibility score). Standard errors clustered by values of the poverty score are reported in parenthesis. 
Table C.5: Heterogeneous Effects on Vocational Choice - Local Linear Regressions

\begin{tabular}{|c|c|c|c|c|}
\hline & (1) & $(2)$ & $(3)$ & $(4)$ \\
\hline Sample & All & All & Low GPA & High GPA \\
\hline Takeup $\times$ Low GPA & $\begin{array}{c}0.133^{* * *} \\
(0.037)\end{array}$ & & & \\
\hline Takeup $\times$ High GPA & $\begin{array}{c}0.003 \\
(0.030)\end{array}$ & & & \\
\hline Takeup $\times$ Low Distance & & $\begin{array}{c}0.047 \\
(0.033)\end{array}$ & $\begin{array}{c}0.087 \\
(0.058)\end{array}$ & $\begin{array}{c}0.026 \\
(0.040)\end{array}$ \\
\hline Takeup $\times$ High Distance & & $\begin{array}{c}0.085^{* *} \\
(0.034)\end{array}$ & $\begin{array}{c}0.127^{* *} \\
(0.058)\end{array}$ & $\begin{array}{c}0.064 \\
(0.041)\end{array}$ \\
\hline $\mathrm{P}$ value $\mathrm{H} 0$ : treatX_low $=$ treatX_high & 0.000 & 0.122 & 0.350 & 0.177 \\
\hline Observations & 3908 & 3908 & 1846 & 2062 \\
\hline Clusters & 2093 & 2093 & 1280 & 1394 \\
\hline
\end{tabular}

